أثر صعوبة الفقرة وحجم العينة ِِّ دقة معادلة درجات الاختبارات باستخدام نظرية استجابة الفقرة (IRT)

$$
\text { وزارة التربية والتعليم، مملكة العاطي المحروق* البحرين }
$$

قُبل بتاريخ: آ|

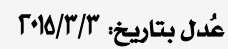

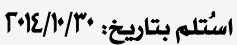

المستخلص: هدفت هذه الدراسة إلى معرفة أثر صعوبة الفقرة وحجم العينة ِِّ دقة معادلة درجات الاختبارات باستخدام نظرية استجابة

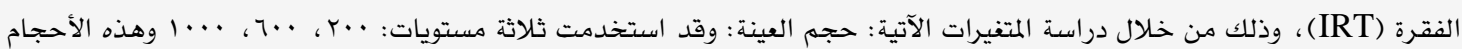

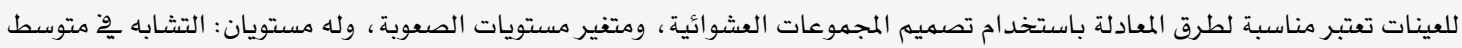

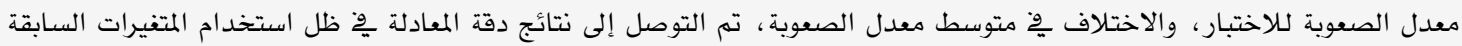

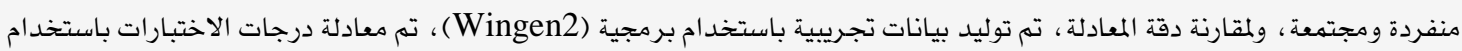

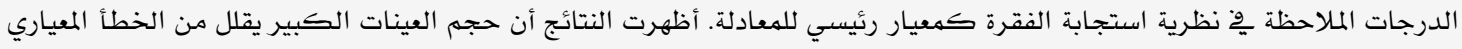

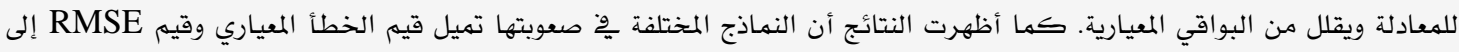

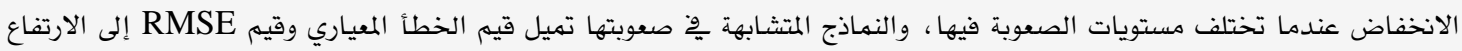
عندما تتشابه مستويات الصعوبة فيها. كلمات مفتاحية: نظرية استجابة الفقرة، معادلة الاختبارات.

\title{
Effect of Item Difficulty and Sample Size on the Accuracy of Equating by Using Item Response Theory
}

Yousef A. Al Mahrouq*

Ministry of Education, Kingdom of Bahrain

\begin{abstract}
This study explored the effect of item difficulty and sample size on the accuracy of equating by using item response theory. This study used simulation data. The equating method was evaluated using an equating criterion (SEE, RMSE). Standard error of equating between the criterion scores and equated scores, and root mean square error of equating (RMSE) were used as measures to compare the method to the criterion equating. The results indicated that the large sample size reduces the standard error of the equating and reduces residuals. The results also showed that different difficulty models tend to produce smaller standard errors and the values of RMSE. The similar difficulty models tend to produce decreasing standard errors and the values of RMSE.
\end{abstract}

Keywords: Item Response Theory (IRT), equating test.

*yousif.almahrooq@moe.gov.bh 
بالنظرية الححديثة في القياس التي تفتـرض ض

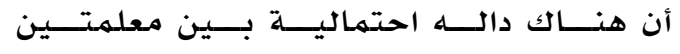
احســاهما تتعلــق بقــلدرة (Two Parameters) الفرد و الأخرى تتعلق بالفقرة التـي يختبـر بها، وبانتالي فان هذه النظريسة تهـدف إلـى

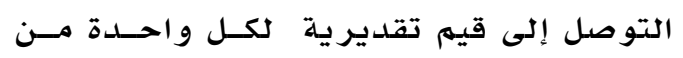

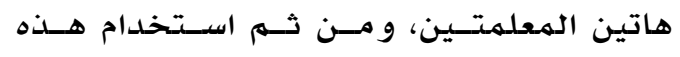
القيم في تقدير احتمالية الإجابة الصديحة

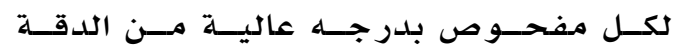

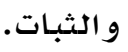

لقد بين هامبلتون وسوامنثيان (Hambelton) ( \& Swaminathan, 1985) لنظرية اسـتجـابـة الفقـرة منهــا: أن تقــدير قدرة الفرد يكون مستقلا عن عينـة الفقـرات التــي تطبـق عليــه، أي أن تقـــيـرات القــدرة لكلأفـر اد متحـــررة مــن خصـــائص الفقـر ات المستخخدمهة في تقـلدير القـدرة (Item free). كذذك ومـع افتر اض وجود عدد كبير مـن الأفراد، يكون تقدير مـعالم الفقرات مسـتقلا عن عينـة الأفراد التي استخدمت في في تقـدير

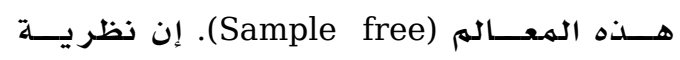

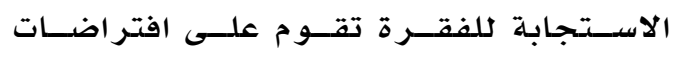

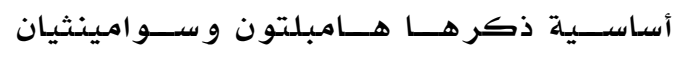
وهـيـ (Hambelto \& Swaminathan,1991) افتراض أحادية البعـــ (Unidimensionality)،

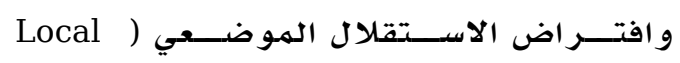

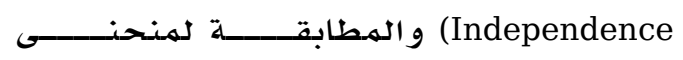
خصــائص الفقـرة (tem Characteristics Curve (ICC) (Speediness) استجابـة الفقرة على وجود عدد من النهــاذج الرياضــية المسسـتخدمهة لمطابقــة النهــوذج للبيـانات التي مـن أهمها: النهماذج اللوجسـتيه

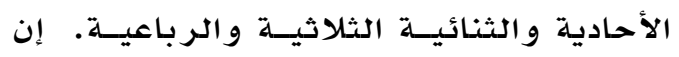
النجاح في استخدام نهاذج نظرية الاسـتجـابة للفقرة يقوم على مسجموعـة مـن الهتطلبـات منها: أحادية البعد ثلاختبـار، مطابقة فقـرات الاختبار للنهموذج المسـتخدم، حجــم العينــة المســتخدمـة، تـوفر البـر مـجيـات الهحاســوبية

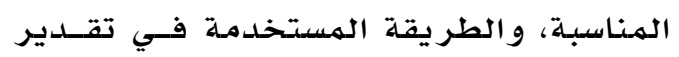

سيطر ت نظريسة القيـاس النفسـي التربـوي

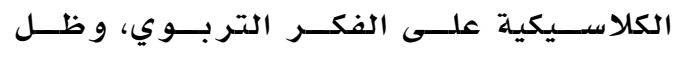
العاملون بالقياس النفسي يستخدمون مبــادئ و أسس هـذه النظريـة فـي بنــاء الاختبــارات و المقــايسيس بأشــكالها المهتخلفــة، و تفســير الدرجات المتحققة عليها لفترة طويلــة مــن

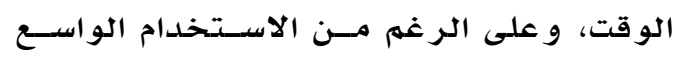

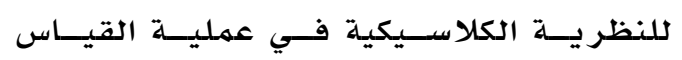
النفسي و التربري إلا أنها تعاني مــن جوانـبـ Linden, قصور أشار إليها هامبلتون و لنــان منهــ (Hambelton \& Van der 1982)

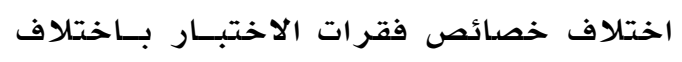
عينات المهفحوصين المستخدمين في معسايرة الفقـر ات، إذ أن خصــائص فقــرات الاختبــار تعتمدد على مستوى وتوزيع قدرات أفراد هذه إده العينات، فصعوبة الفقرات تكون أعلى مها هي في الواقع في حالة اختيار عينــة تكـون في مســتوى قـدر تها أعلـى مــن مســتوى قـدرة الأفر اد في المهجتهـع، كها تكـون أدنـي مهـــا يجب في حانة اختيار عينـة تكون في مستوى قدر تها اقل مـن مستوى قدرة أفر اد الهـجتهـع. كذلك من جوانب القصور التي تعاني منهـا

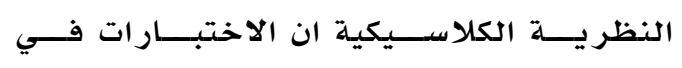
النظرية الكلاسيكية لا تزودنا بتقدير دقيـق

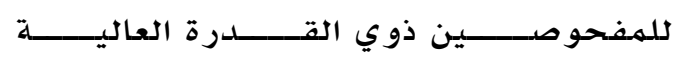
و للمفحوصسين ذوي القدرة الهـتدنية ؛ وذلـك الـوك لأن الاختبـارات الهبـيـية على أسـاس النظريسة الكلاسيكيـة في القياس تأخذ في اعتبـارها عند

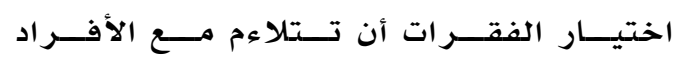
متو سطي القدرة. و لتلافي العيوب التــي ظهـرت فـي النظريسة

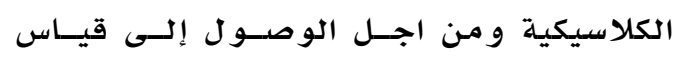

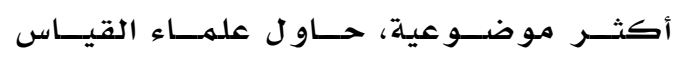
الهعاصرون الاستفادة من التقدم التكنولوجي في التوصل صإلى طرق سـيكو متريسه جديـدة تسـاعد في التغلب على بعض نواحي القصور في النظرية الكلاسيكية، لذلك انبثقـت عـن هذه الطرق الجديــدة نهـاذج تسـهى نهـاذج السهـات الكامنـة أو نظرية الاستجابة للفقرة Item Response Theory) 


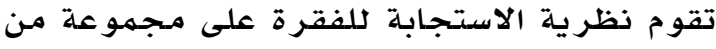
الافتراضات، تؤدي إلى التفسير الصحيح لنتائج الاختبار ومعادلته، بشرط أن يتهم تطبيقها بشكل

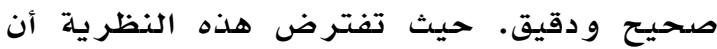
أداء المفحوصين في الاختبار يمكن تفسيره عن

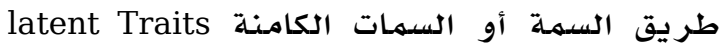
المراد قياسها، والتي لا يمكن قياسها بصورة

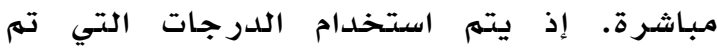
تقديرها للمفحوص في تلك السمة في التنبؤ بأدائه في اختبار ما أو في فقرة من الاختبار؛

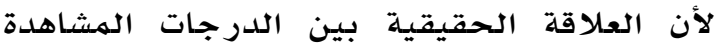

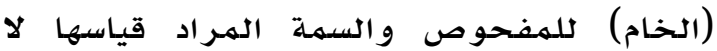

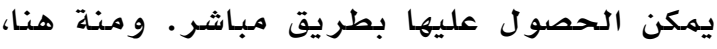
تقوم نظرية الاستجابة لمفردة الاختبار بوصف

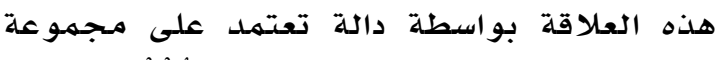

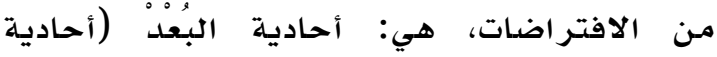
السمة) Unidimensional حيث يقيس الاختبار

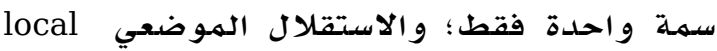
independence على فقرة اختبار عن أدائه على فقرة أخرى. وكذلك جعل السمات الأخرى التي تؤثر على أنى

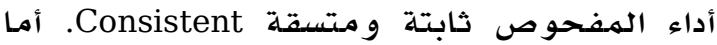

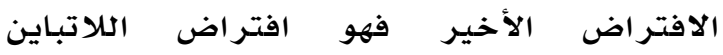
Invariance Parameters

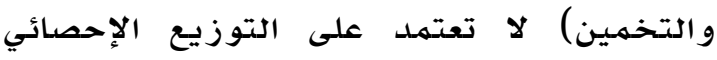
للسمة المر اد قياسها؛ وأن المعالم التي تصف الدئ أداء

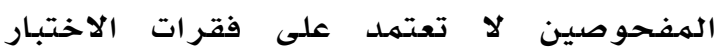
.(Hambelton, Swaminathan, \& Rogers, 1991)

\section{خطوات معادلة الاختبارات باستخدام نظرية}

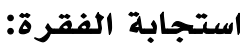

وضح كل من من هامبلتون وسواميناثان (Hambleton \& Swaminthan, 1985)، و وكذلك كولن وبرينان (Kolen \& Brennan, 1995)، الخطوات الضرورية لمعادلة الاختبارات بواسطة نظرية استجابة الفقرة؛ وهي كالآتي:

اختيار التصميه المناسب لمعادلة الاختبار مع الأخذ بعين الاعتبار
Hambelton ) معالم الفقرات و معلمة القدرة .\& Swaminathan, 1991

لقد ظهرت عدة تطبيقات عملية لنظرية استجابة الفقرة ومن هذه التطبيقات: الكشف عن التحيز

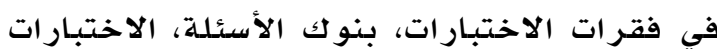
التكيفية، بناء الاختبارات و تحليلها و وتقنينها، وكذلك معادلة الدرجات على صور الاختبار المختلفة. ويصنف المختصون في القياس القياس

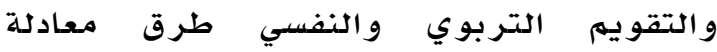
الاختبارات إلى نوعين: الطرق والنق التي تعتمد على

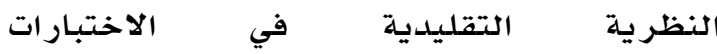
فئما Classical Test Theory.(CTT) فيُصنَفُ ضمن الطرق التي تعتمد على النظرية

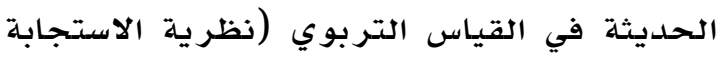

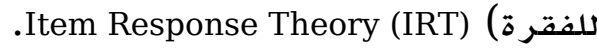

إن معادلة الاختبارات المعتمدة على الدرجات الخام raw scores ضمن النظرية التقليدية للاختبارات قد لا تكون مرغوبة؛ وذلك بسام بسبب

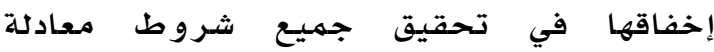
الاختبارات، و وهي العدالة و والمساو اة، و والتماثل، والكلاتباين (Hambleton \& Swaminathan, 1985). لذلك، فإن معادلة الاختبار عن طريق نظرية استجابة الفقرة (النظرية الحديثة في القياس التربوي و النفسي-Item Response Theory) تحل

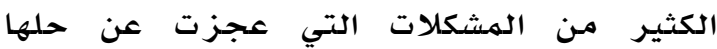
النظرية التقليدية في الاختبارات؛ بشرط أن الن النير

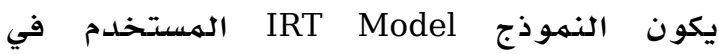
النظرية الحديثة هذه مطابقاً للبيانات المُعدة

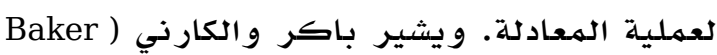
\& Alkarni, 1991, p 147 إلى أنه من الإسهامات الكبيرة للنظرية الحديثة في القياس التربوي التهاسي التهامات والنفسي -والتي اصطلح على تسميتها بنظرية الاستجابة للفقرة (-) Item Response Theory في الممارسة التربوية، وذلك لقدرتها

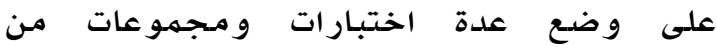

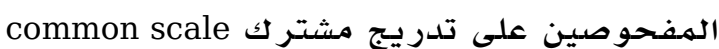

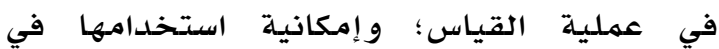
المعادلة الأفقية و الر أسية للاختبار . 
هنات فقرات مشتركة بين صورتي

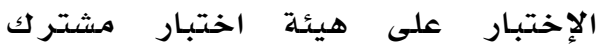
Anchor Test

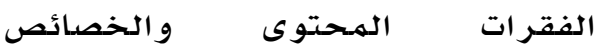

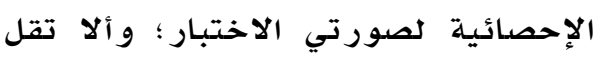

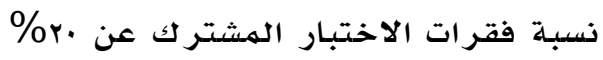

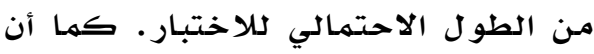

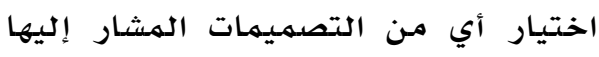

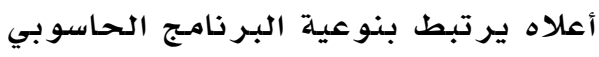

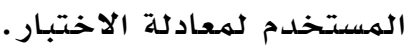

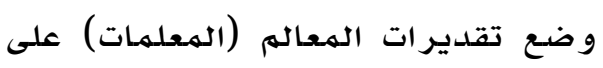

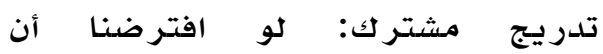

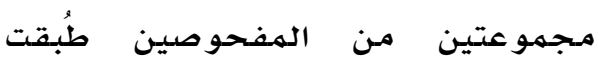

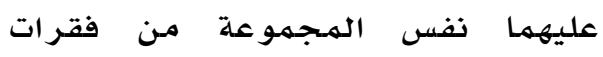

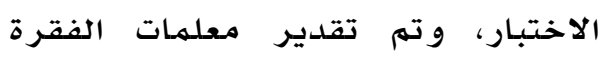

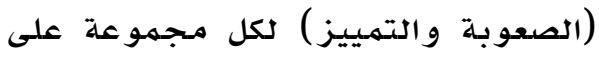
حده، وأن النهوذج الرياضي الهستخدم

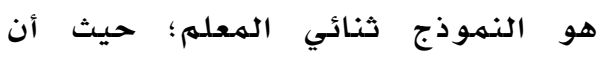

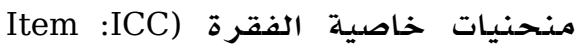
م) مستقللة عن (Characteristic Curves الهمجموعتين المستخدمتين رسمر هذه المنحنيات. ويمكن أن نستتنتج من ذلك أن تقديرات معلمات الفقرات متطابقة في كل من الهـمبوعتين على حلده. ويجب هنا الأخذ بعين الاعتبار أثر خطأ

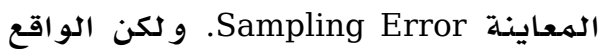
ليس كذلك! إذ يجب إجراء تحويل رياضي معين يوحد التدريج في عملية

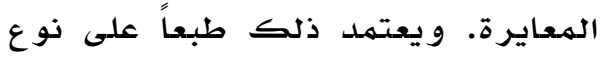
البرنامـج الحاسوبي الهستخلدم في إجر اء عملية التحويل الرياضي للحصول على إنى

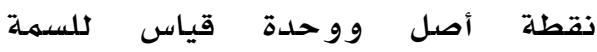
و لهستوى الصعوبة. ويكون متوسط

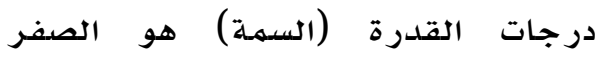
و انحر افها الهعياري هو الواحد الصحيح (برنامـ LOGIST يمكن أن يحقق ذلكي). ويجب ملاحظة أن عملية التحويل الرياضي التي تضع الدرجات وتقدير ات

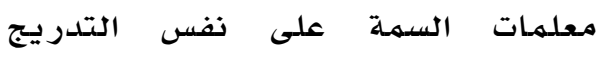

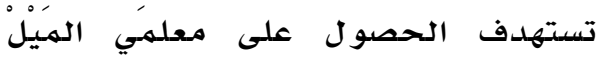

خصائص مجهمو عة الهفحوصين وطبيعة الاختبار ات المر اد معادلتها.

إختيار النهموذج المناسب الذي يطابق

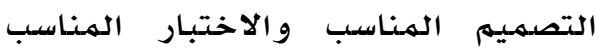
(نموذج راش أو غيره من نماذج هذه الهناس النظر ية). (نهودج)

بناء تدريج مشترك يربط العلاقة بين

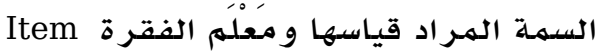
.Parameter

إختيار التدريج المناسب لوضع درجات

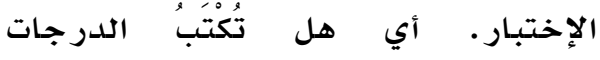

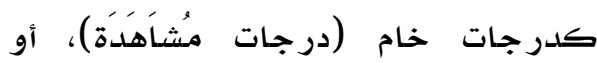
على صورة درجات قُدرة ability scores، أو على صورة درجات حقيقية مقدرة estimated true score

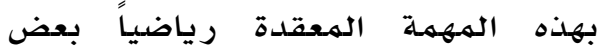

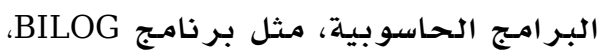

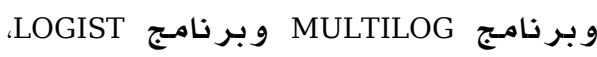

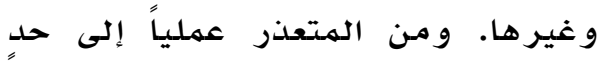

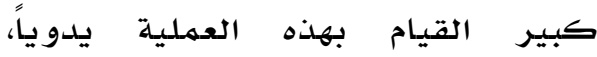
وخاصدة في هذه النظرية.

Cooker \& Eignor, ) ويوضح كوكر وايجنور

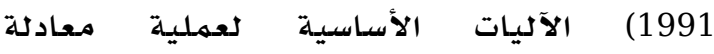

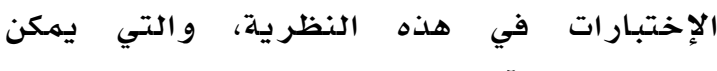
إيجاز ها في الآتي:

إختيار التصميم المناسب: هناك ثلاثة

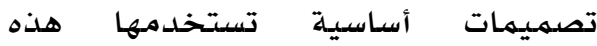

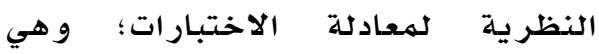
تصميم الهـجموعة الهفردة، وتصميم

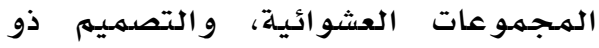

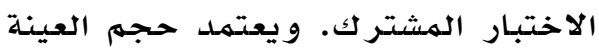
الملائم لإجراء معادلة الاختبار بشكل بشكل صحيح على العدد الملائم للمفحوصين للحصول على مستقيرة

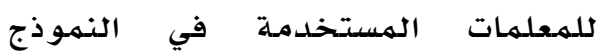

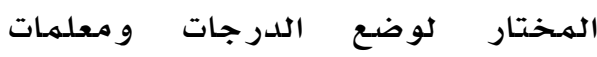
القدرة (السهمة) على تلدريج و احلد. و في لودي عمليـة المعايرة هذه نحتاج إلى عينـة

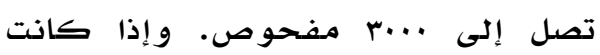


= $\hat{P}_{j}(\theta)$

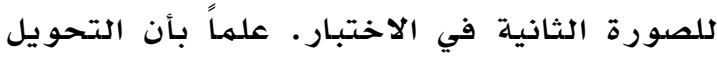

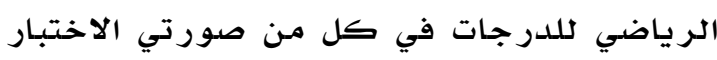

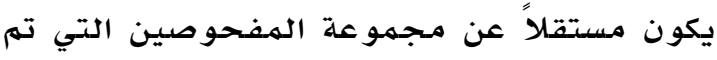

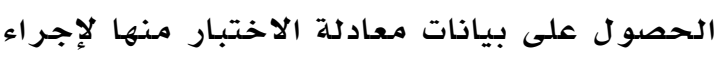

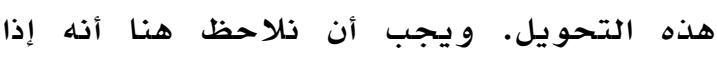
كانت الصورة القديمة للاختبار المراد الدئ معادلته

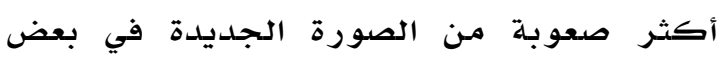

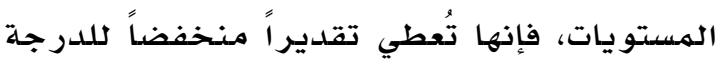

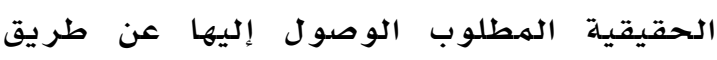
تقدير درجة السمة. (الدوسري، ع...r)

الفوائد العملية والتطبيقية لمعادلة الاختبارات

باستخدام نظرية استجابة الفقرة

تشير نتائج الأبحاث التي أجريت على معادلة

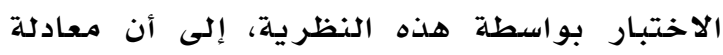

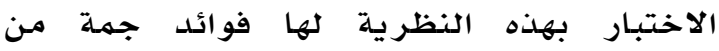

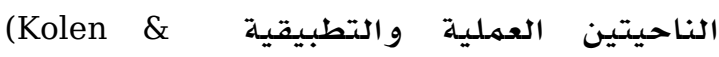
Brennan, 1995) معادلة الاختبار بهذه النظرية هي الأفضل

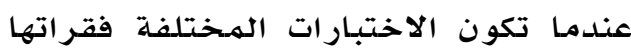

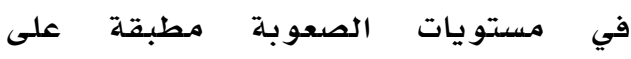

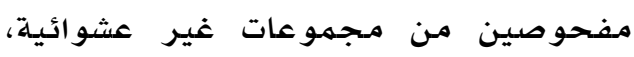
تختلف في مستو يات السمة المر اد قياسها. معادلة الاختبار بهذه النظرية، وبسبب خصائصها المشروحة سلفارة سلفاً، تؤدي إلى بلى تحويلات رياضية للدرجات تكون مستقلة التهاتل عن مجموعة أو مجموعات المفحوصين التي طُبقت عليها الاختبارات.

المعادلة بنظرية IRT هي أفضل من الفئل نظريتها في النظرية التقليدية للقياس

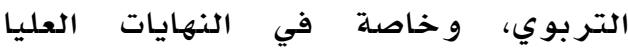
لتدريج الدرجات، حيث غالباً ما تتهم عملية التهات التيات اتخاذ القرارات الهامة، وحيث يمكن معادلة الدرجات الخام مـع كل قيم درجات لسمة. المعادلة بهذه النظرية تسمح باستخدام

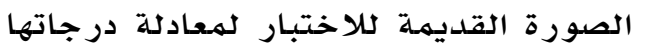

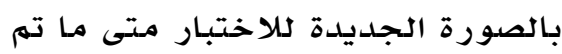

و والقاطع Interception Slop يكون الوسط الحسابي والانحراف

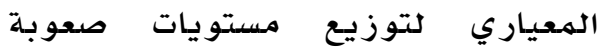
الفقرات، التي تم تقدير ها في عملية

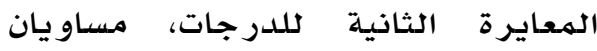

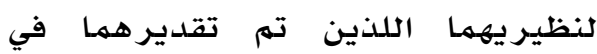

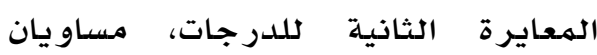

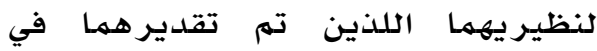
المعايرة الأو لى للدرجات.

معادلة درجات الاختبار: تُعتبر عملية معادلة الاختبار منتهية إذا تم تقدير

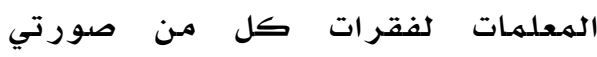
الاختبار المستهدف، وتم وضعها على تدريج مشترك، وتم كذلك الحتهار الحصول

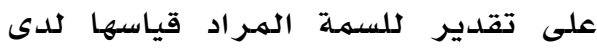

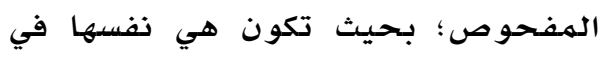
أي من صورتي الاختبار . ويؤخذ خطأ

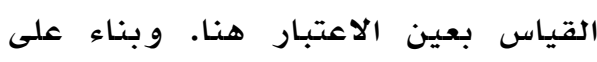
ذلك، يكون التعبير عن الدرجات الخام الامنيار بما يكافئها من درجات التعات السمة. أما إذا الدات الهات

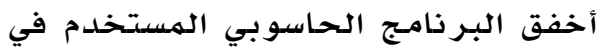

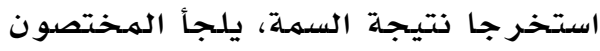

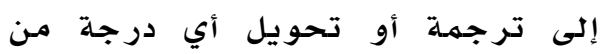
درجات القدرة إلى الدمة الدرجة الدولئ الحقيقية درجة

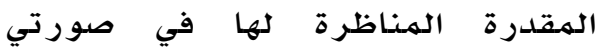

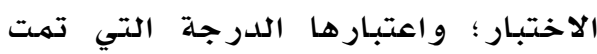

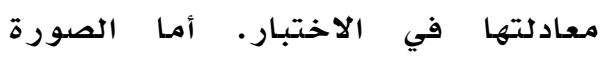
الرياضية للدوال التي تربط بين التبار، درجات المات الهورة

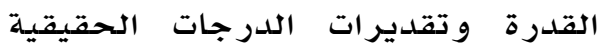
فهي كالتالي:

$$
\begin{aligned}
& \hat{r}_{x}=\sum_{i=1}^{n} \hat{P}_{i}(O) \\
& \hat{r}_{y}=\sum_{j=1}^{n 1} \hat{P}_{j}(O)
\end{aligned}
$$

= $\hat{T}_{x}$ الأولى من الاختبار.

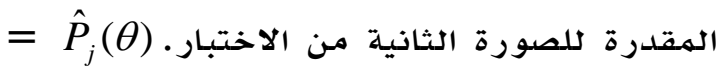

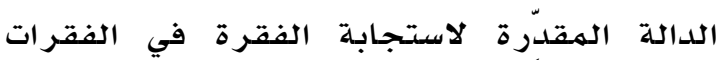

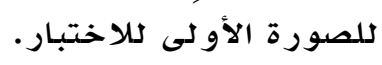


Logistic Function يجعل الدالة اللوجستية

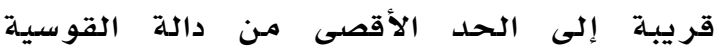

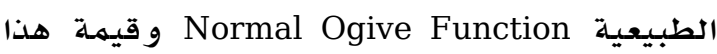

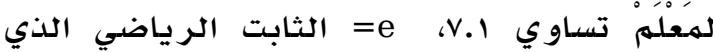
يحول الدالة التي تربط بين الدرجة الخدام

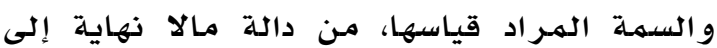
دالة احتمالية تحصر العلاقة بين أداء الطالب

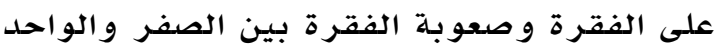

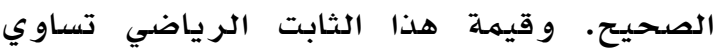
$. r, \wedge \mid V$

طرق معادلة الاختبارات باستخدام نظرية استجابة الفقرة

هناك ثلاث طرق رئيسية لهعادلة الاختبار بهذه النظريـة و هي(Kolen \& Brennan, 1995).

(ا) معادلة الاختبارات باستخدام درجات القدرة Ability Score Equating (الستمة)

في هذا النوع من معادلة الاختبارات نفتر ض أن

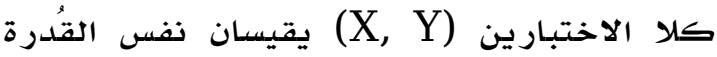

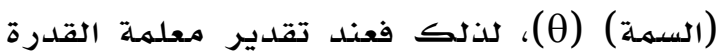

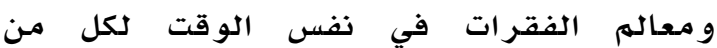
الاختبارين فإننا نضعهما على نفس التدريج حيث 0x=0y. و للقيام بهذه الخطوة فإننا نحتاج إلى معادلة درجات القدرة أثناء معايرة calibration تقدير معلمات الفقرات، كالصعوبة و والتمييز. وينتج عن ذلك علاقة خطية بين تدريج القدرة

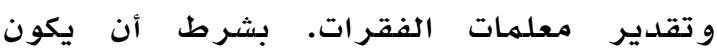
التقدير ان منفصلين. و لتحديد القيم (ӨX) و (Өy) يمكن استخدام عدة طرق نذكر منها:

طرق الانحدار (Regression methods). طريقة المتوسط الحسابي و الانحر اف الهعياري (Mean and sigma). لهوئه طر يقة (Robust Mean and Sigma).

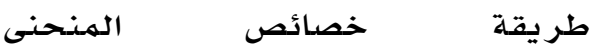
.(Characteristic curve methods)

$$
\begin{aligned}
P(\theta) & =\frac{1}{1+e^{D(\theta-b)}} \\
P(\theta) & =\frac{1}{1+e^{D a(\theta-b)}} \\
P(\theta) & =\frac{1}{1+e^{D a(\theta-b)}}
\end{aligned}
$$

وضع الدرجات في كلا الاختبارين، و كذلك تقديرات معلمات القدرة، على تدريج و احد.

معادلة الاختبار بهذه النظرية تسمح بمعادلة الاختبار على مستوى الفقرة الواحدة، وذذك قبل الشروع في تطبيق الاختبار في صوره المتعددة، وقبل تطبيق

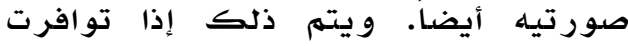

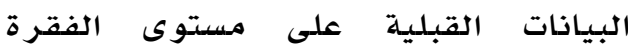
الواحدة، مـع إمكانية معايرتها. ثم يتم تمات وضع تقديرات المعلمات على تلدريج مشترك، وهذه الخاصية لا يمكن الحصول عليها من خلال معادلة الاختبار بواسطة

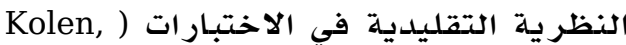
(1988

يمكن التعبير عن العلاقة الرياضية بين درجة

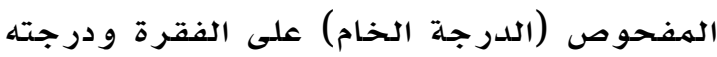

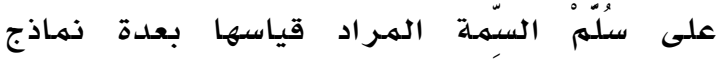
رياضية في نظرية استجابة الفقرة؛ وهي نموذج

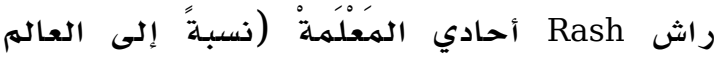

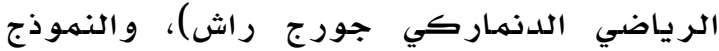

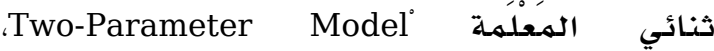

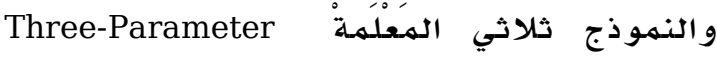
Model و ويعبر عن هذه النهماذج رياضيا كها يـأتي: - n - n نموذج راش أحادي المعلهم

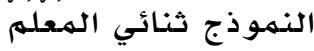

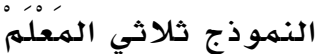

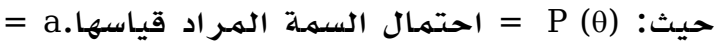

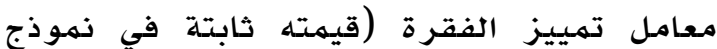
(راش).

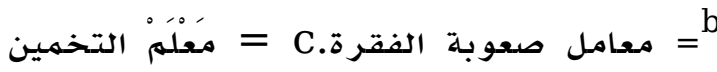

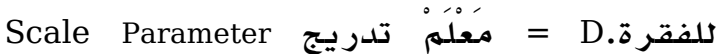


الدرجات الخام ليست مثل العلاقة بين الدرجات الحقيقية. ففي الدرجات الخام تكون أدنى درجة الدئ هي الصفر، و في الدرجات الحقيقية تكون أدنى الدى الدئ

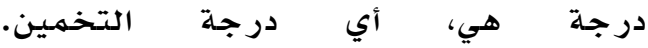
$\stackrel{\sum}{\sum}<<=$

تقوم معادلة الاختبار بطريقة الدرجات الخام

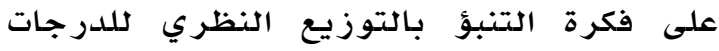
الخام للاختبار عن طريق بناء التواء التوزيع التكراري الذي تمثله الدالة (

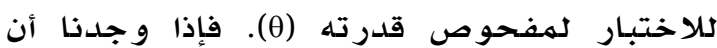
دوال الاستجابة لكل فقرة من فقرات الاختبار

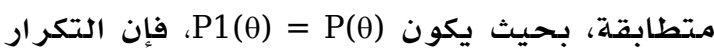

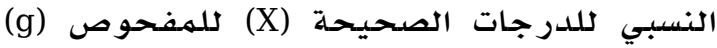
يمكن حسابه رياضياً بالمعادلة الآتية ضمن لهن لهن توزيع ذي الحدين: كما يمكن معادلة الاختبار بهذه الطريقة للوصول إلى دالة التكرار النسبي ذي الحدادين

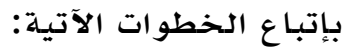

$$
\int\left(X \mid \theta_{g}\right)=\left(\begin{array}{l}
n \\
x
\end{array}\right) p_{x} Q^{n-x}
$$

وضع معلمات القدرة و معلمات الفقرات

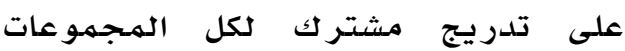

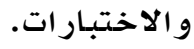

r. الحصول على التوزيع التكراري الهامشي marginal frequency distribution كلدرجات في الاختبار الأول باستخدام

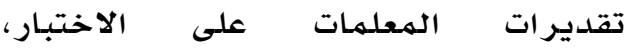
و تقديرات معلمات القدرة، باستخدام الدالة

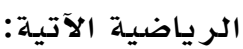

$$
\int(X)=\sum_{1-1}^{n} \int\left(X \mid \theta_{g}\right)
$$

r. تكرار الخطوة رقم (r) للاختبار الثاني. ؟. إجراء معادلة للاختبار بطريقة الرتب

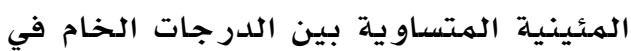

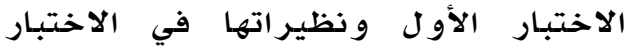

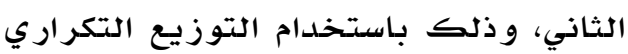

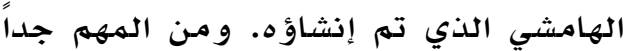

(ب) معادلة الاختبارات باستخدام الدرجة الحقيقية True-Score Equating في النظرية التقليدية للاختبارات، يُطْلق على النق الدرجة المتوقعة للمفحوص (g) على الفقرة

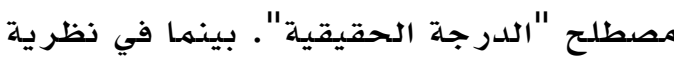
استجابة الفقرة، تصاغ رياضياً على الصورة:

$$
\sum_{1=1}^{n} P_{1}\left(\theta_{g}\right)
$$

فلو افترضنا أن الاختبار بصورتيه يقيس نفس

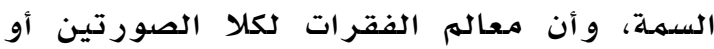
الاختبارين قد تم وضعهما على نفس التدريج؛

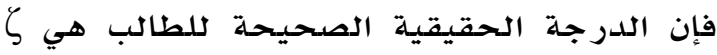

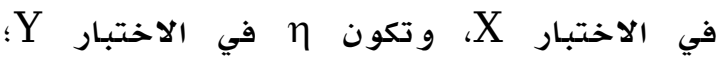

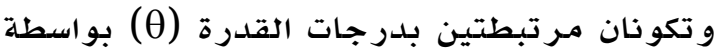

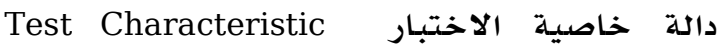
Curve، بالصورة الرياضية الآتية (Lord, 1980).

$$
\eta=\sum_{1=1}^{n} P_{1}(\theta) \quad \zeta=\sum_{1=1}^{n} P_{1}(\theta)
$$

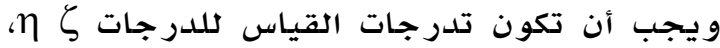

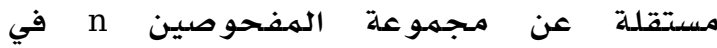
الاختبار، و أن يكون تدريج قياس درجات القدرة

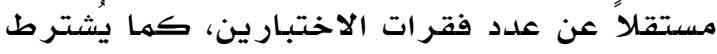
أن تكون مستويات صعوبة الفقرات متطابقة في الاختبار ين.

ومن عيوب معادلة الاختبار بهذه الطريقة، ان

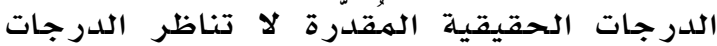

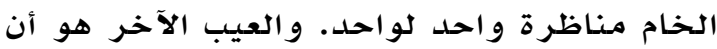

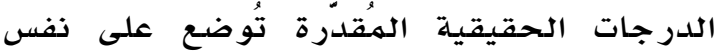
Peterson et. al., التدريج مـع الدرجات الخخام) .(1989)

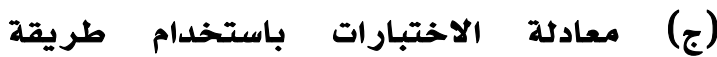

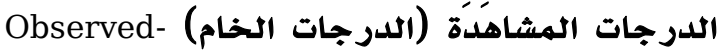
score Equating

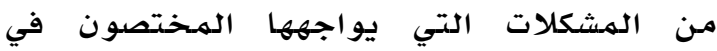

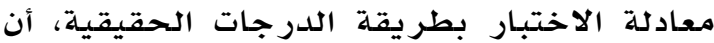
هذه الطريقة لا تلنتج عنها درجات معادلة للهفحوص الذي درجته الخخام أدنى من مستوى

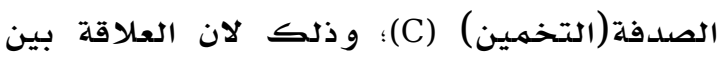


أمـا (Mao, 2006) فقد أجرى دراسـة هدفت إلى فحص دقة تقديرات الأخطاء المعيارية لمعادلة كيرنيل تحت ظروف مختلفة من: حجم العينة

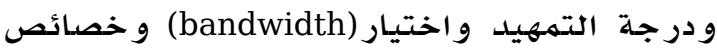
توزيعات الدرجة وذلك بـاستخدام تصميم المجمهوعات العشوائية لتقدير الخطأ الهعياري للمعادلة (SEE) حيث تم اعتباره معيار ا للمعادلة.

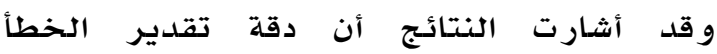
المعياري في المعادلة (SEE) كان أفضل في الهن العينات ذات الحجهم الكبير وذات إل (bandwidth) الكبير، كذلك أثارت النتائج أن الدرجات العالية مـن التههيد تميل إلى إنتاج حجم أكبر

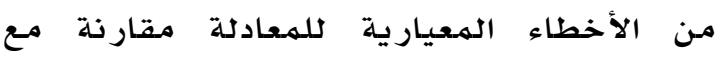
الدرجات المنـخفضة من التههيد.

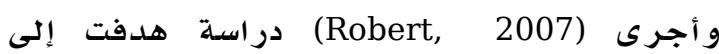
مقارنة الدرجات الحقيقية في نظرية استجابة الفقرة ونظرية استجابة الفقرة بالاعتمـاد على الهيه

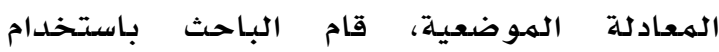
اختبارات مختلفة و بنهماذج مختلفة لفحص الأداء؛ وذلك لتقييهم نتائج معادلة الدرجات الحقيقية مـع معادلة الدرجات المشاهدة في نظرية استجابة الفقرة تحت ظروف مختلفة: طول الجذع الهشترك، فقدان بعض البيانات، طريقة التدريج، وتوزيع قدرات المفحوصين. تم تقييم

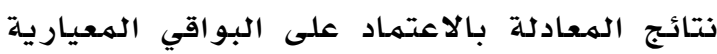

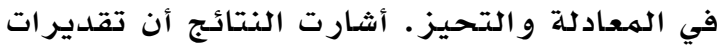

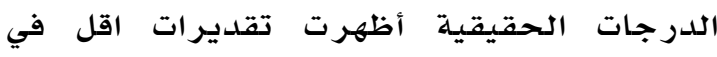
معياري التحيز و البواقي المعيارية، كذلك لهم

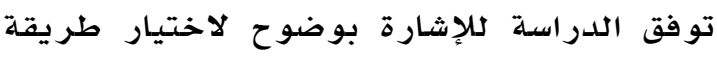
التدريج لكلا طريقتي الهعادلة. و أجرى (Youngwoo, 2007) دراسة هدفت إلى (بد) مقارنة الخطأ المعياري للمعادلة باستخدام طرق

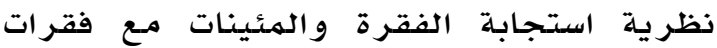

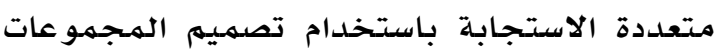
غير المتكافئة ذات الاختبـار المشتر ك. استخدمت

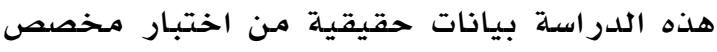
لتقييم الكتابة، حيث عدلت البيان البيانات الأصلية لعمل خمس صور من الاختبارات وثلاث صور أخرى لاختبار، وتم تطبيق معايير الخطأ المعياري و البواقي المعيارية على طرق المعادلة
في معادلة الاختبار بهذه الطريقة تغطية

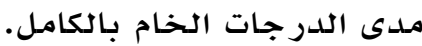

أما فيما يتعلق بالدراسات السابقة المتعلقة بمعادلة الاختبارات باستخدام نظرية استجابة

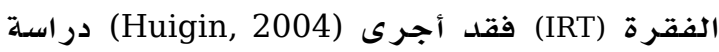
هدفت هذه الدراسـة إلى التحقق من طرق طرق

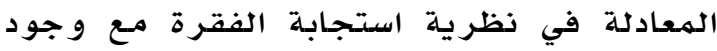
القيم الشاذة، تم توليد بيانات تجر يبية باستخدام

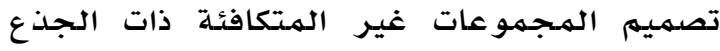

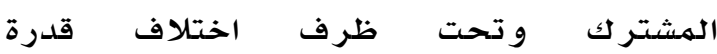

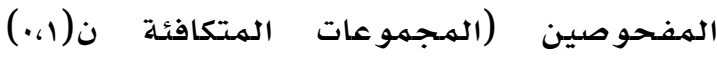

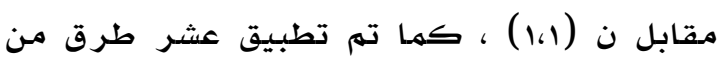

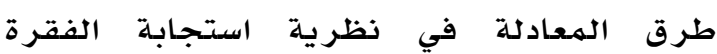

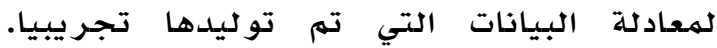

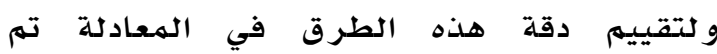
استخدام الأخطاء المنتظمـة. أشارت النتائج انه عندما تكون القيم الشاذة متضمهنة في البيانات،

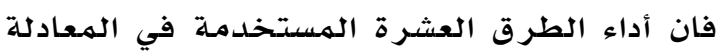
تؤدي إلى ظهور اختلافات في قدرة المفحوصين و في توزيع نقاط الدرجة للقيم الشاذة.

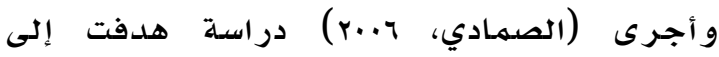
الكشف عن فاعلية طرق تصحيح الصواب و الخطأ المتعدد و تأثيرها على دقة معادلة الاختبارات

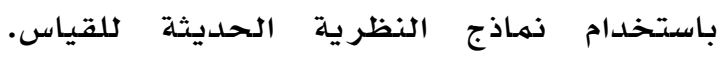
و لتحقيق هذا الهدف قام الباحث ببناء اختبار

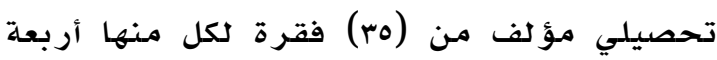

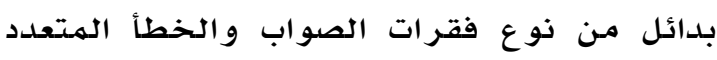
في مبحث الرياضيات. تكونت عينـة الدراسـة مـن

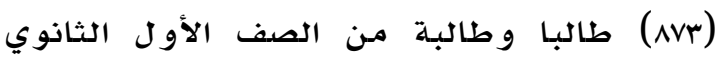
موزعين على عشرة مدارس تشهمل تسعا و عشرين شعبـة في تخصصدات الأدبي والإدارة الهعلو ماتية

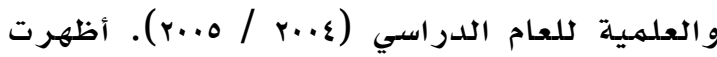
النتائج أن طريقة التصحيح الرابعة -وهي إعطاء

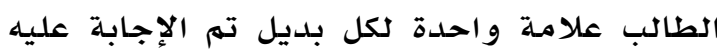

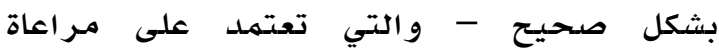
الهعرفة الجزئية، كانت الأكثر دقة في قياس

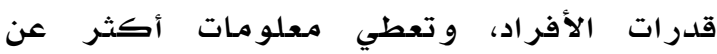
الاختبار، كما كانت الأكثر فاعلية في معادلة

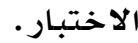


و أجرت (Amanda, 2008) در ماسة هدفت إلى مقارنة طرق المعادلة في النظرية الكلاسيكية

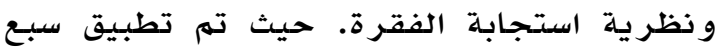

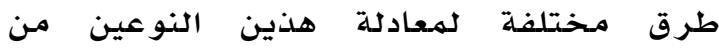
الدرجات وهي: ثلاث طرق كلاسيكية (طريقة توكر الخطية، الطريقة غير المهمهدة وطريقة

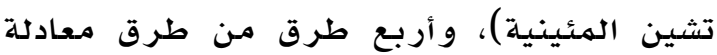

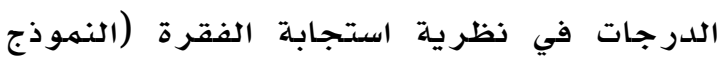

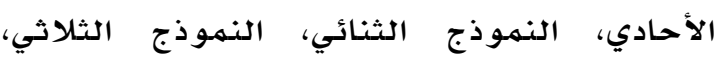

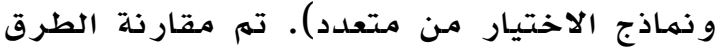
السبعة المستخلدمة في هذه الدهار اسـة باستخدام بيانات حقيقية تم جمعها من تطبيق اختبار SAT و بيانات مولدة. أشارت النتائج أن الطريقة التي أنتجت أقل قيمة للتحيز في البيانات الحقيقية و المولدة هي طريقة توكر الخطية. من مجمهل الدراسـات السابقة يمكن القول إن هذه

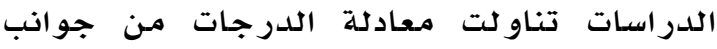

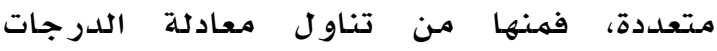

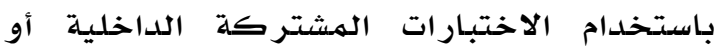

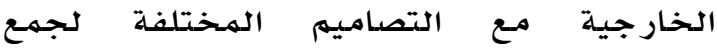

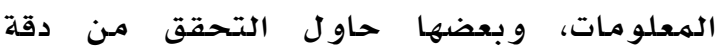

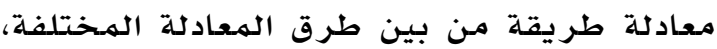
كما تطرقت بعض الدراسات إلى الححديث عن العوامل التي تؤثر في دقة معادلة الدرجات مثل:

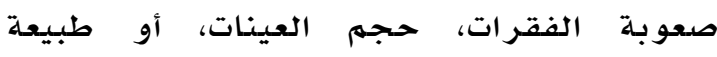

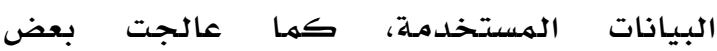
الدراسات اثر زيادة كل من عدد فقرات الاختبار

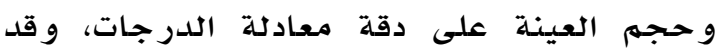
لاحظ الباحث أن بعض هذه الده الدراسـات عانت من

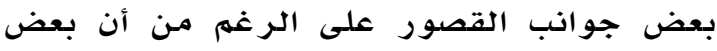

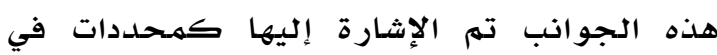

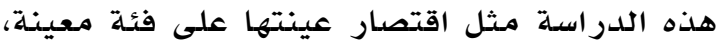
إضدافة إلى اقتصار بعض الدراسل ماستات على طريقة واحدة أو الثنتين من طرق معادلة درجات

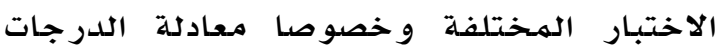
باستخدام المئينات أو المعادلة الخطية. و لعل هذه الدراسـة تتميز عن الدراسـات السابقة

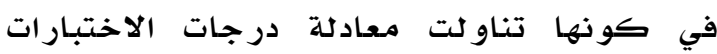
متعددة الاستجابية باستخدام IRT و التي له تبحثث
الستة الهستخدمة في هذه اللدراسة، وبحجم

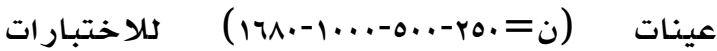

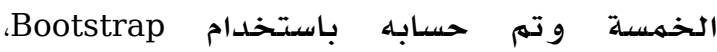

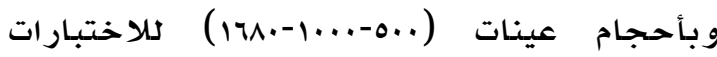
الثلاثة. أشارت النتائج بصورة عامـة أن طريقة المعايرة المشتركة أظهرت أخطاء معيارية

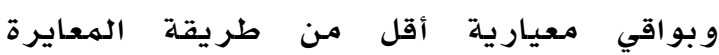

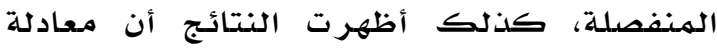

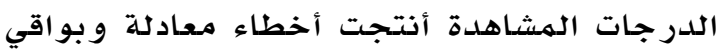
معيارية اقل من معادلة الدرجات الحقيقية.

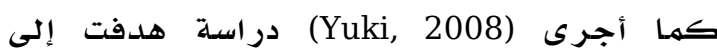
مقارنة الطرق المعلمية والكلامعلميلة في نظرية استجابة الفقرة في معادلة الدرجات باستخدام

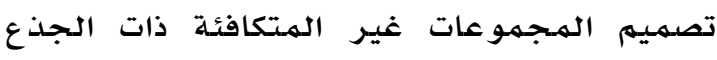

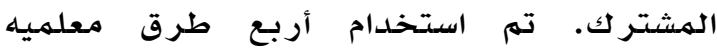
لمعادلة الدرجات في نظرية استجابة الفقرة:

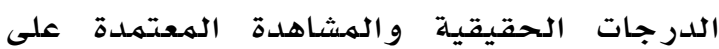

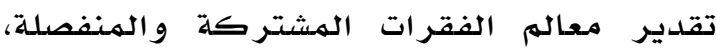
بالإضـافة إلى استخدام أربع طرق لامعلمية وهي: معادلة الدرجات الحقيقية و المشاهدة بالاعتماد على توزيع كيرنيل. وحتى تتهم المقارنة في الأداء بين الطرق المستخلممة تم الاعتماد على له ذوعين من البيانات: تم توليد بيانات بالاعتماد

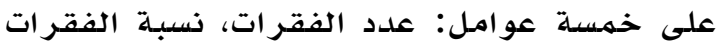

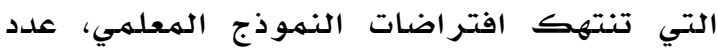

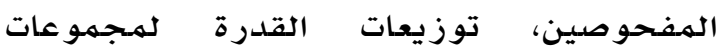

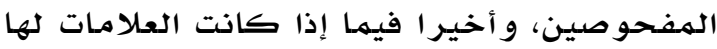

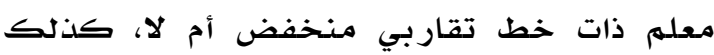
تم تطبيق بيانات حقيقية لفحص سلوك طرق

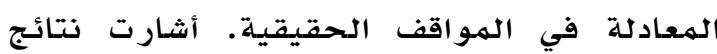

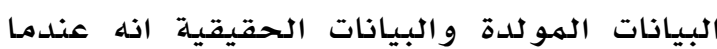
تتحقق افتراضـات النهموذج، تكون الطرق المعلمية

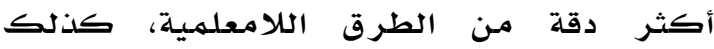

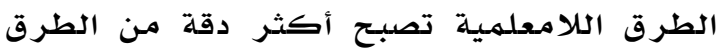

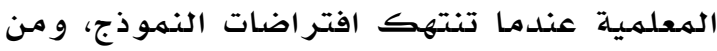

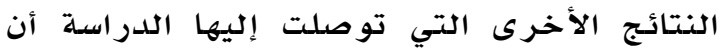

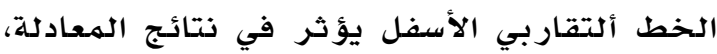

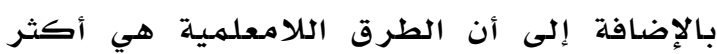

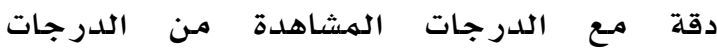
الحقيقية في معادلة الدرجات. 
وحجم العينة. ويهكن صياغة مشكلة الدراسة بالتساؤل الآتي: ما أثر طرق نظرية استجابة الفقرة في دقة معادلة درجات الاختبـارات المتعددة الححدو دئ وبالتحديد فان هذه الدراسـة تحاول الإجابة عن الإن

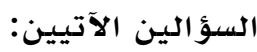

ا. ما أثر صعوبة الاختبار وحجم العينة في

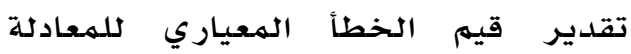
عند (Standard Error of Equating-SEE) النقاط المهتلفة على سله الدرجات؟ ما أثر صعوبة الاختبار وحجم العينة في

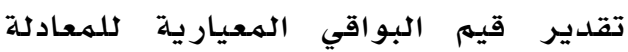
(Root Mean Standard Error of Equating-RMSE) على سلهم الدرجات؟

أهمية الدراسة

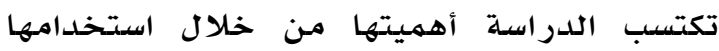

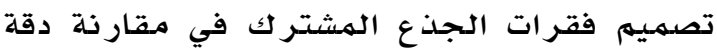

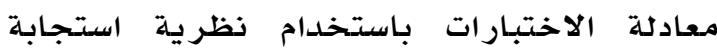

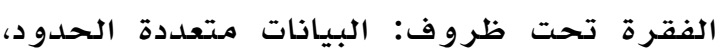

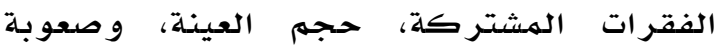

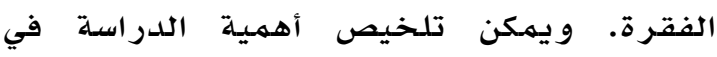

$$
\text { الجوانب الآتية: المعزه }
$$

الإسهام في إلقاء الضوء على مدى دقة طرق

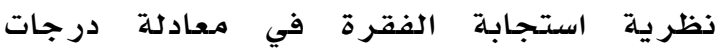

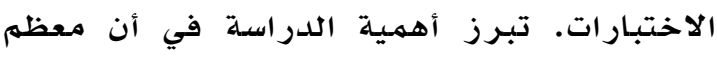

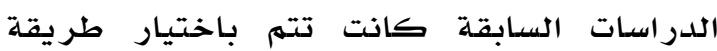
الهئينات أو طريقة الهعادلة الخطية، بينها في هذه الدراسـة تم استخدام طريقة نظرية استخابة الهرية

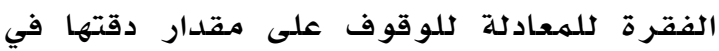
معادلة درجات الاختبارات.

أهداف الدراسة

توفير معلومـات و إرشادات تسـاعد الهـهتمين في بناء الاختبارات لانتقاء أفضل الطرق في معادلة الدرجات و تطبيقها بكل يسر وسهو لة.
سابقا -في حلدود علم الباحث-بصورة كافية، كذلك تتميز هذه الدراسـة بتناو لها لـمتغير ات عديدة مثل حجم العينة، صعوبة الفقرات؛ للوقوف على مدى فاعلية ودقة نظرية استتجابة الفقرة في معادلة الدرجات. كما تتميز هذه

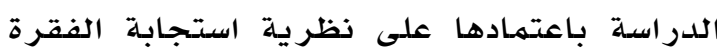
كمعيار للهقايسة والهفاضلة للحكمم على دقة المعادلة، و ذلك أن معظم الدراسـات السـابقة كانت تستخدم الطريقة المئينية للمفاضلية بين طرق المعادلة الهـختلفة. مشكلة الدراسة و أسئلتها

عندما يتم استخدام و وتطبيق الاختبار بشكل بهل متكرر، فان فقرات الاختبار يمكن أن تصبيح

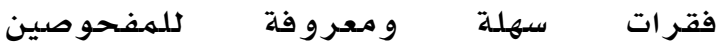
الهستقبليين؛ لذلك يته إعداد نماذج متعدددة

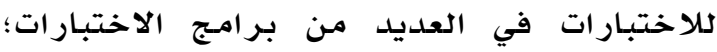

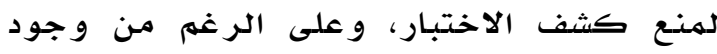
النهماذج المتعددة لكلاختبـارات و التي تم بناؤها

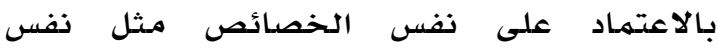

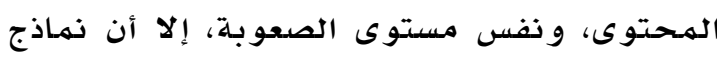

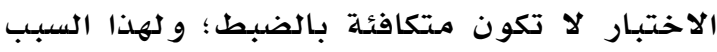
فان بعض المفحوصين الذين يأخذون الاختبار الأسهل سيكون لهم أفضلية على أولئك الذين

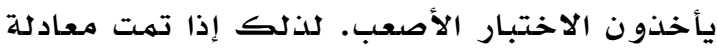
درجات الاختبارات المختلفة بطريقة علمية الاحية صحيحة، فان المفحوصين سوف يحصلون على نفس الدرجات بغض النظر عن أي اختبار يتم التقدم لله. من هنا، هدفت هذه الدراسـة إلى معرفة أثر صعوبة الفقرة وحجم العينة في دقة معادلة

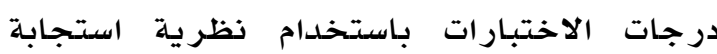

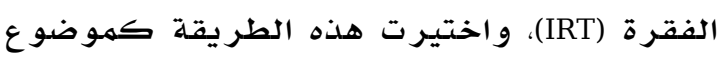

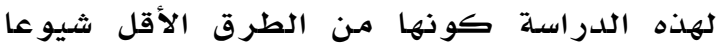
واستخدامـا في معادلة الاختبارات. وبعبـارة

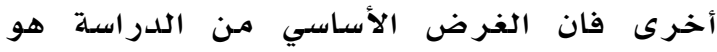
التحقق من دقة معادلة درجات الاختبارات ذات الجذع المشتر ك للمهجمو عات المتكافئة باستخدام طرق نظريـة استجابة الفقرة في معادلة درجات الاختبارات تحت ظروف اختلاف صعوبة الفقرة 


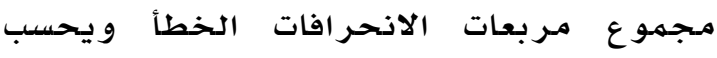

الخطأ المعياري للمعادلة بالمعادلة الآتية:

$$
S E E=\sqrt{\left[\frac{1}{n-1} \sum_{1}^{n}\left(\hat{e}_{x}\left(y_{k}\right)-\bar{e}_{x}\left(y_{k}\right)\right]^{z^{\prime}}\right.}
$$

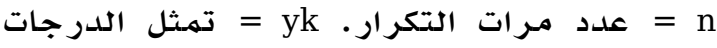
على النموذج ex(yk) y = هي الدرجة المعادلة

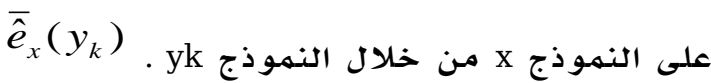

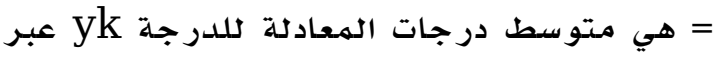

$$
\text { مـر ات التكر ارات. - مكوسي }
$$

الجذر التربيعي لمتوسط مجموع مربعات الانحر افات الخطأ Root Mean Squared Error) و يمكن حساب جلذر متوسط مربع الأخطاء المعيارية (RMSE) مـن خلابن جلاد المعادلة مئل

$$
R M S E=\left[\frac{1}{n_{s}} \sum \frac{1}{n_{e}} \sum_{j}\left(y_{j}-E_{j}\right)^{2}\right]^{\frac{1}{2}}
$$

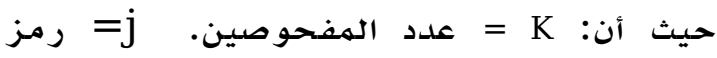

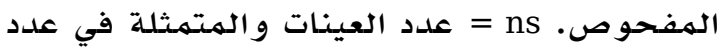
مر ات توليد البيانات. ne = عدد المفحوصين في

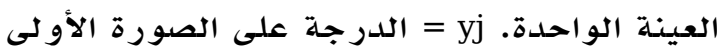
للهمفحوص j في ضوء درجته على الصورة

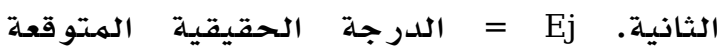
للهفحوص على الصورة الأولى.

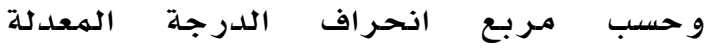
للمفحوص على الصورة الأولى عن درجته

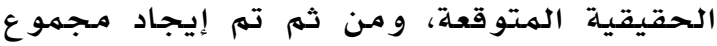
مربعات انحر افات كل أفراد العينة في كل مـرة، وحسب متتوسط مجهموع مـربعات الانحر افات في كل عينة، وون ثم متوسط عدد مـرات التوليد

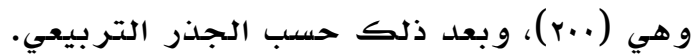

\section{إجراءات جمـع البيانات}

استخدمت هذه الدراسة نظرية استجابة الفقرة

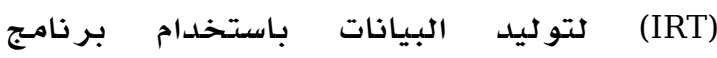

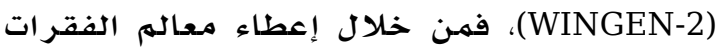
وخصائص الأشخاص، فان البرمجية تستطيع

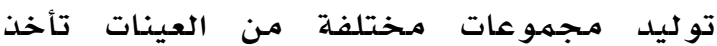

اقتصسار هذه الدراسـة على طريقة واحلدة من طرق معادلة درجات الاختبار المختلفة و هي طريقة الهعادلة باستخدام نظرية استجابة الفقرة. استخدام الخطأ المعياري ومتوسط مـربع

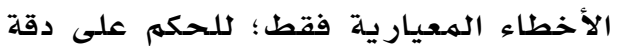
المعادلة. اقتصار الدراسـة على بيانات تجريبية مو لدة باستخدام بر مجيلة (Wingen2).

\section{مصطلحات الدر اسة}

معادلة درجات الاختبارات: هو إجراء إحصائي يتم فيه تحويل سلهم الدرجات على أحد الاختبارات إلى سلهم الدرجات على على الاختبـار

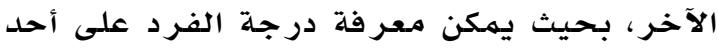
الاختبار ات إذا علمنا درجته على الاختبـار الآخر . البيانات متعددة الحدود: وهي فقرات اختباريه

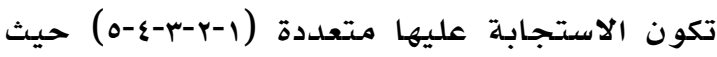
يكلف المفحوص بتحديد الاستجابة التي ير اها مناسبـة.

\section{الطريقة والإجر اءات}

هدفت هذه الدراسة إلى معرفة دقة طرق نظرية

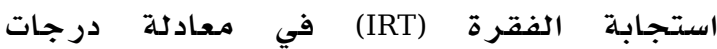
الاختبارات متعددة الاستجابة، وفيما يلي ووصفا للمنهجية المتبعة في هذه الدراسة. أو لا: تصميم الدراسة ومتغير اتها تكونت متغيرات الدراسـة المستقلة من: حجهم

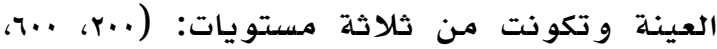

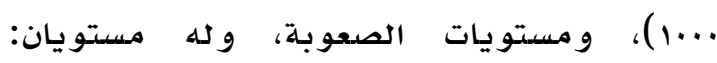
(التشابه في متوسط معدل الصعوبة كلاختبار والاختلاف في متوسط معدل الصعوبة). ورفي

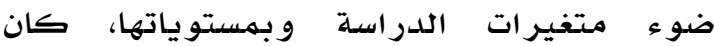

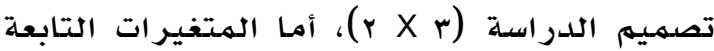
فقد تمثلت في معيار الحكمم على دقة معادلة

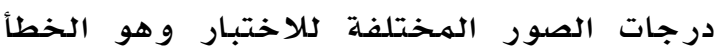
الهعياري للمعادلة، والجذر التربيعي لكتوسط 
r. في كل عملية توليد للبيانات يتمم توليد نموذج يتكون من (1.0) بشكل عشوائي دـ لـ .X

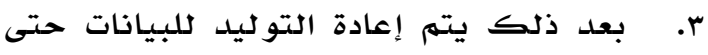

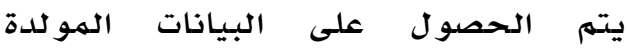
كلاختبار ع. إعادة تو ليد البيانات للنموذج Y. ه. بعد الحصول على البيانات لكلا النموذجين يتم تطبيق إجراءات معادلة الدرجات المستخدمة في هذه الدر اسـة.

7. بعد ذلك يتم إعادة الخطوات السـابقة ..0

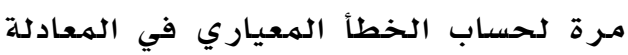

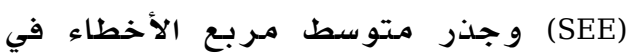
المعادلة (RMSE) لكل درجة خلاجل درل درجات العات

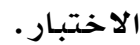

\section{البر مجيات المستخدمة}

برنامج (Wingen2)

استخلدم هذا البـرنامـج في توليد الاستجابات

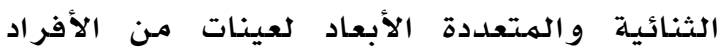

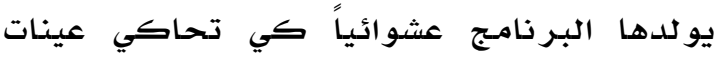

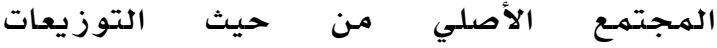

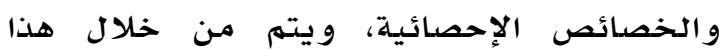
البر نامـج إنتاج العديد من عينات الاستجابة تصل إلى (1.................. فقرة ذات الأحجام الهختلفة التي لها خصائص العينات الهناظرة لها بالمجتهـع الأصلي نفسها. وبالتالي يمكن من خلال هذه البرامـج الحصول على عينات عديدة ذات أحجام كبيرة يصعب الحصول عليها من الهـجتمع الأصلي مهما يوفر

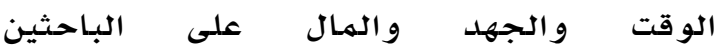
(Hambleton \& Han, 2007)

\section{مقاييس المعادلة (إجراءات المعادلة)}

ككل مستوى من طول الاختبار و تشابه مستويات

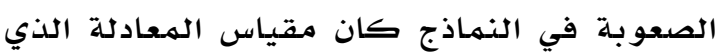
تم اعتمـاده هو باستخدام طرق المعادلة باستخدام الدرجات الملاحظة.

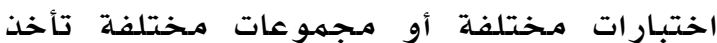

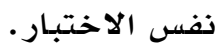

تو ليد بيانات الاستجابة على الفقرات و معادلة

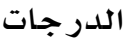

تم توليد البيانات باستخدام برنامـج (Wingen 2) لتوليد عينات عشوائية تمثل مجتتهـع التوزيعات ولإيجاد معيار و معادلة الدرجات وتقييم دقة الهـعادلة وفق الخطواد معيار وات معادلة الآتية:

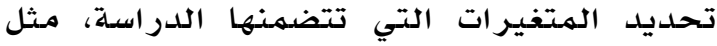
حجم العينة وصعوبة الاختبار والتوزيع الذي الذي تقع تحته معاله الفقرات، و غير ها مـن المتغير ات الهـر اد در استها.

توليد البيانات و وفقاً لنموذج نظرية استجابة الفقرة الهـلوب.

تقدير المعالم مثل: معلمة الصعوبة، التمييز،

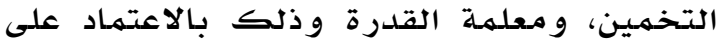
استجابات الفقرة التي تم تو ليدها. تكر ار الخطوة السـابقة (N) من المـرات لكل خلية في التصميهم البحثي. مقارنة النتائج التي تقيس تأثير المتغيرات الهـر اد در استها.

تحليل النتائج الخاصدة بكل خلية باستخدام

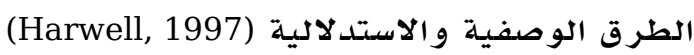
رابعا: خطوات توليد البيانات الهستخدمة في هذه الدر اسلة

اعتمد ت ت هده اللدراسـة على توليد البيانات

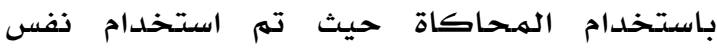
إجراءات المعادلة في المستويات الثلاث لهجم لهم لهماه العينـة لكل متغير (طول الاختبـار، حجم العينة)،

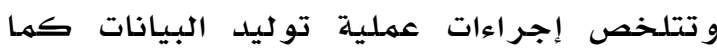

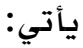
ا. للنهموذج X، يتم حساب معاملات الصعوبة

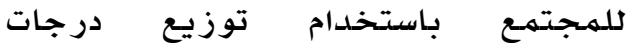

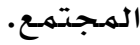


جدول 1 (15

الخطأ المعياري للمعادلة لطريقة (IRT) في معادلة درجات الاختبار المتثابه في مستوى صعوية الفقرات

\begin{tabular}{|c|c|c|c|}
\hline $1 \ldots$ & $7 \ldots$ & $r .$. & حجم العينة \\
\hline \multirow[t]{2}{*}{$r_{6} \leqslant r$} & $r, \varepsilon \vee$ & דr,r & الخطأ المعياري \\
\hline & & & للمعادلة \\
\hline
\end{tabular}

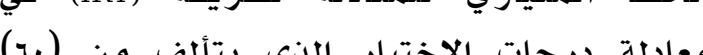

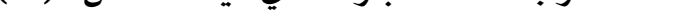

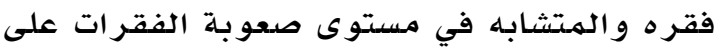
سلهم الدرجات و عبر اختلاف حجم العينات.

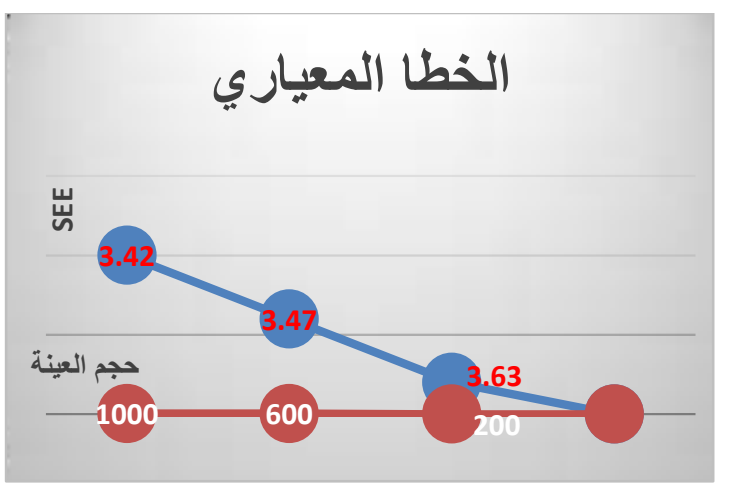

شكل ا. الخطا المعياري للمعادلة لطريقة (IRT) في معادلة درجات الاختبارات المتشابهة في مستوى صعوبة لمعلة الفقرات

يلاحظ من الشكل السابق ان قيمة الخطأ

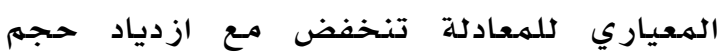

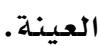

ب-الاختلاف في مستويات الصعوبة:

تم بناء نموذجين للاختبار مكونين من (.) فقرة و مختلفين في مستوى الصعوبة، ثم تم

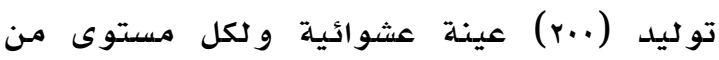

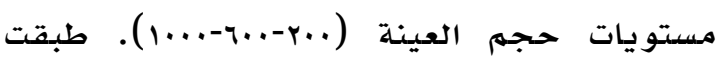

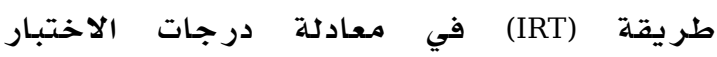
الهستخدمة في هذه الدراسلة على هذه العينات

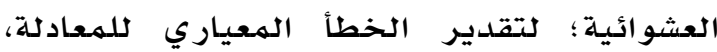
حيث تم التوصل الى النتائج الاتية:

$$
\text { جدول r. }
$$

الخطأ المعياري للمعادلة لطريقة (IRT) في معادلة درجات

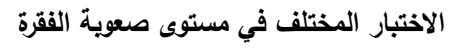

\begin{tabular}{|c|c|c|c|}
\hline $1 \ldots$ & $7 \ldots$ & r... & حجم العينة \\
\hline .9 . & .90 & r.r人 & الخطأ المعياري \\
\hline
\end{tabular}

للمعادلة
تحليل البيانات الهو لدة: التحليل الإحصائي بالإضافة إلى الفقرات التي تم توديدها لنهـاذج

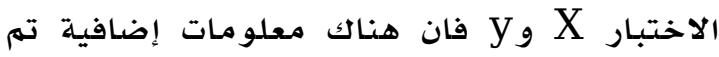

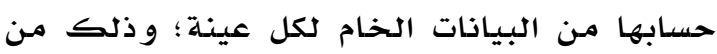
اجل استتخدامها في تقدير وتقييم خطوات المعادلة. وقدل تم تطبيق طريقة المعادلة باستخدام بر مجية (Equating Recipes).

\section{النتائج}

هدفت هذه الدراستة إلى معرفة أثر مة صعوبة الفقرة وحجم العينـة في دقة معادلة درجات الاختبارات باستخدام نظرية استجابة الفقرة

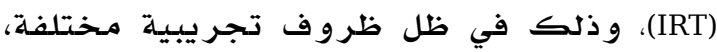

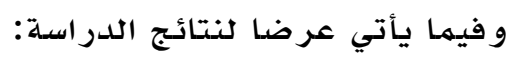
أولا: النتائج المتعلقة بالسؤال الأول: مـا أثر صعوبة الاختبار وحجم العينة في الخطأ

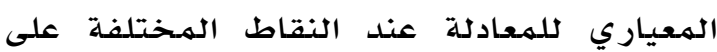

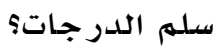
ثانيا: التشابه في مستويات صعوبـة النهماذج: تم توليد نموذجين للاختبار بحيث اشتمل كل

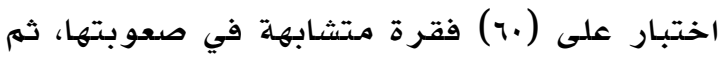

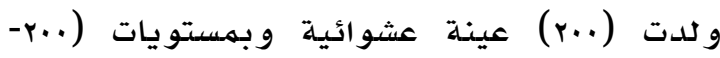

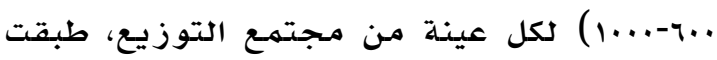

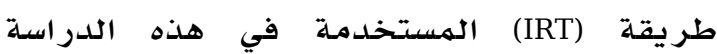
لتقدير خطأ الهعادلة وفيما يأتي توضيح لهذه

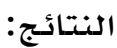

يظهر الجدول (1) أن قيه الخطأ الهعياري

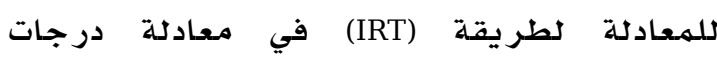

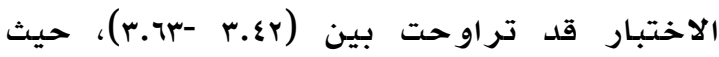

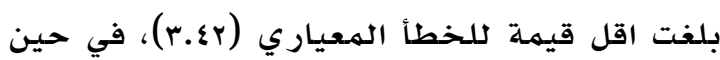

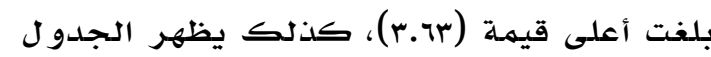
ان قيمة الخطأ المعياري للمعادلة تنخفض مـع

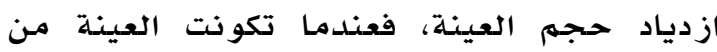

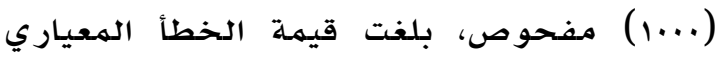

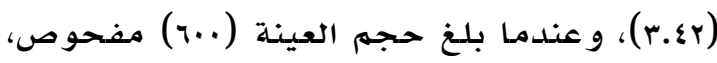

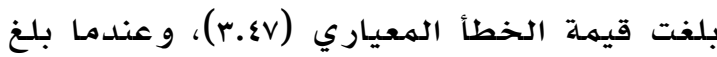

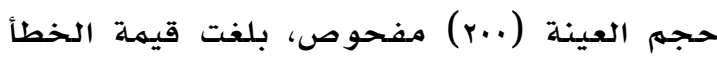
المعياري (rا.r). و يوضح الشكل رقمر (1) قيم 
النتائج المتعلقة بالسؤال الثاني: ما أثر صعوبة الاختبار وحجم العينة في البواقي المعيارية

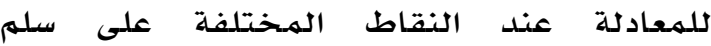

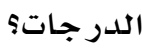

أو لا: التشابه في مستويات صعوبة النهماذج: تم توليد نموذجين للاختبار بحيث اشتمل كل

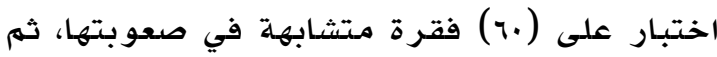

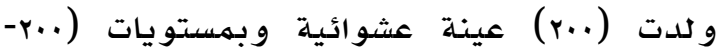

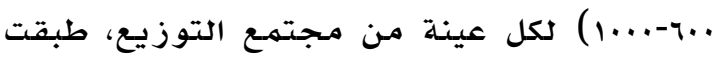

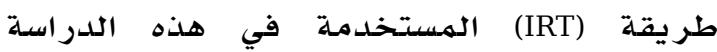
لتقدير جذر متوسطات مربعات الفروق ووفيما يأتي توضيح لهذه النتائج:

يظهر الجدول (r) أن قيم (RMSE) لطريقة (IRT)

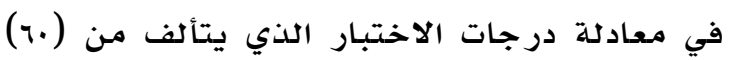

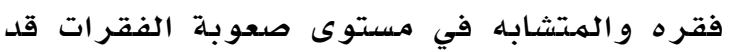

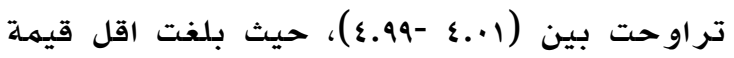

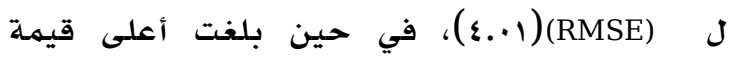

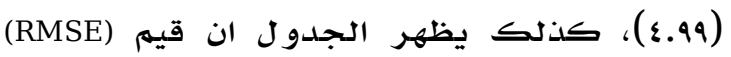
للهعادلة تنخفض مـع ازدياد حجم العينـة، فعندما

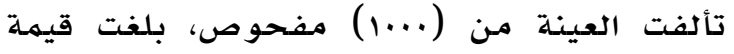

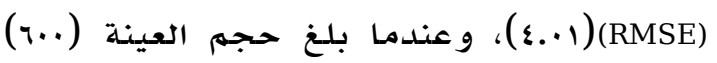

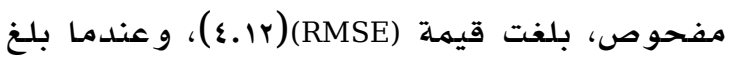

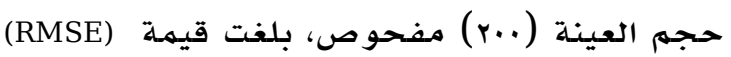

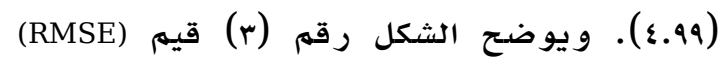
لطريقة (IRT) في معادلة درجات الاختبار الذي وفي

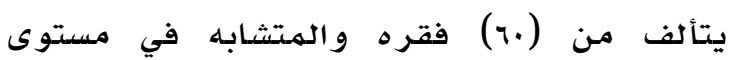
صعوبـة الفقر ات

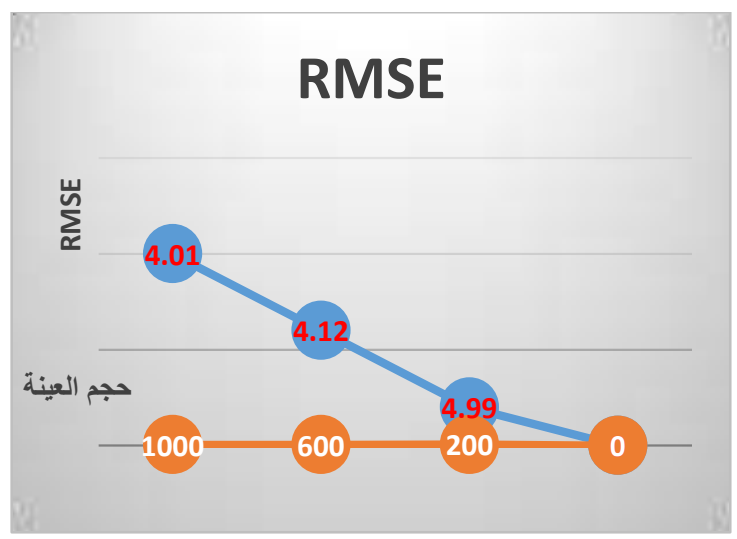

شكل r. قيم RMSE لطريقة (IRT) في معادلة درجات

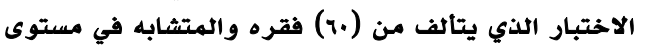
صعوبة الفقرات
يظهر الجدول (r) أن قيهم الخطأ المعياري للمعادلة لطرق لطريقة (IRT) في معادلة

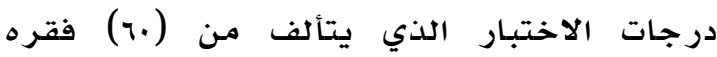

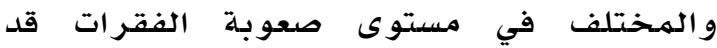

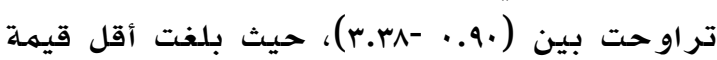

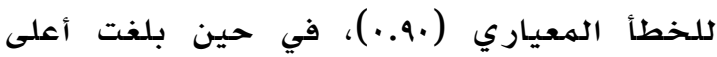

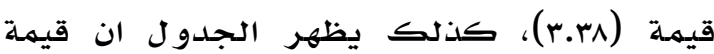

$$
\text { جدول r. }
$$

قيم (RMSE) لطريقة (IRT) في معادلة درجات الاختبار الذي

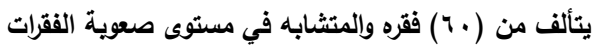
حجم العينة قيم (RMSE)

الخطأ الهعياري للمعادلة تنخفض مـع ازدياد حجم العينة، فعندما تكونت العينة من (.... (1.)

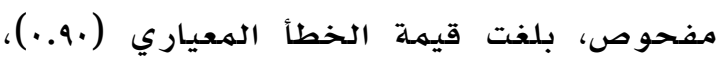

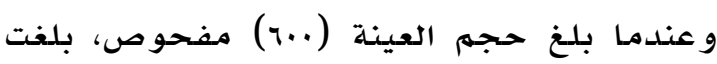

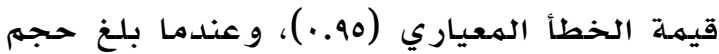

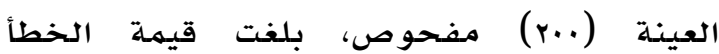
الهعياري (.9..). و يوضح الشكل (r) قيم الخطأ الهعياري للمعادلة لطريقة (IRT) في معادلة

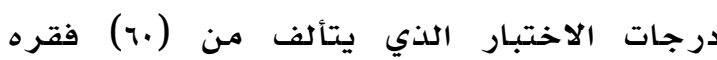
و المهتلف في مستوى صعو بـة الفقرات:

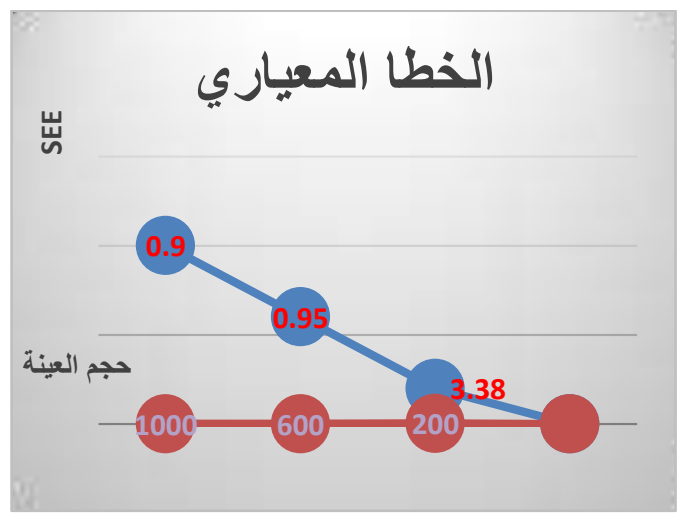

شكل ب. الخطا المعياري للمعادلة لطريقة (IRT) في معادلة

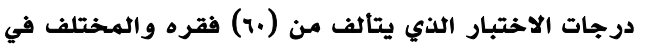
مستوى صعوبة الفقرات

يوضـح الشكل السابق أن قيمـة الخطاً الهعياري

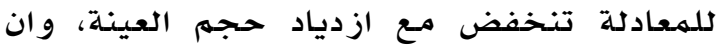
المنـحنيات تميل إلى النزول وتقترب من الصفر

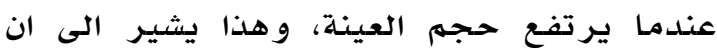
ارتفاع حجم العينة يقلل من قيمة الخطأ الهعياري للهعادلة (SEE). 


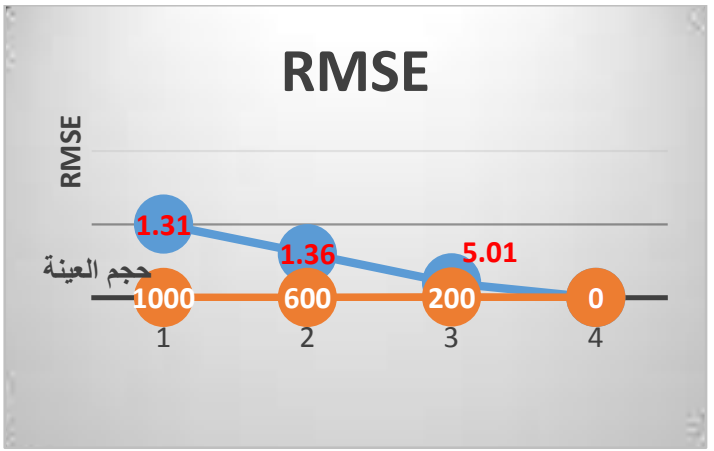

شكل \&. قيم (RMSE) لطريقة (IRT) في معادلة درجات

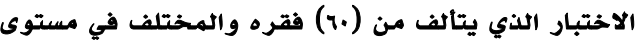
صعوبة الفقرات

يوضتح الشكل السابق ان قيم RMSE تنخفض مـع ازدياد حجم العينهة، كما ان المنحنيات تميل الى الى النزول وتقترب من الصفر عندما ترتفع حجم الهم العينـة، وهذا يشير الى ان ارتفاع حجم العينة يقلل من قيم RMSE. تونمئه

\section{مناقشة النتائج}

مناقشة النتائج المتعلقة بالسؤال الأول: ما أثر صعوبة الاختبار وحجم العينة في الخطا

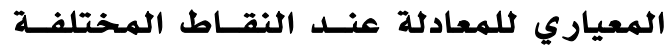
على سلم اللدرجات؟

أظهرت النتائج أن قيم الخطأ المعياري للمعادلة

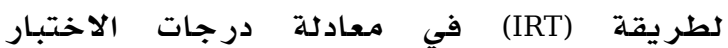
الهتشابه في مستويات الصعوبة قد تراوحت بين

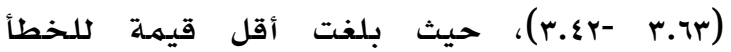

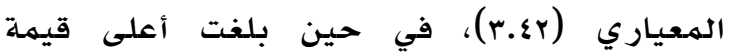

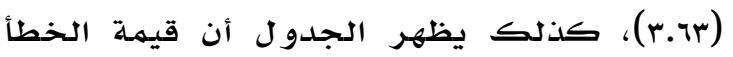

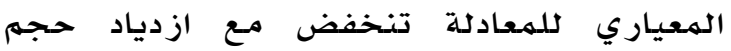

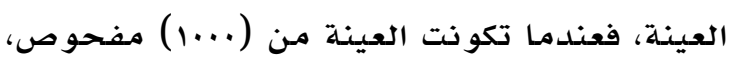

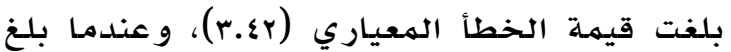

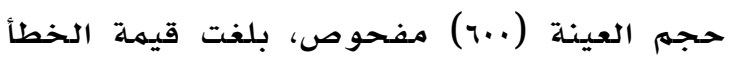

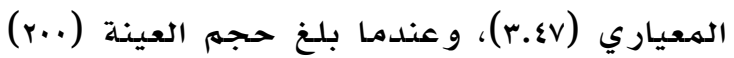

مفحوص، بلغت قيمة الخطأ المعياري (rا.r). كما أظهرت النتائج أن قيم الخطأ المعياري

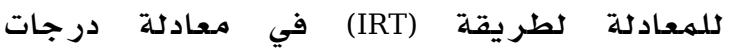
الاختبار الذي يتألف من (.ج) فقره و الهـختلف

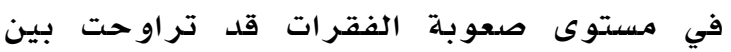

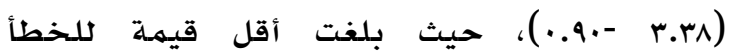

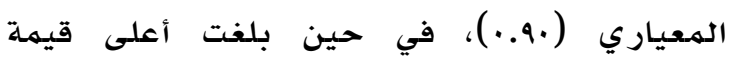

يظهر الشكل السابق ان قيه (RMSE) تتأثر بحجم

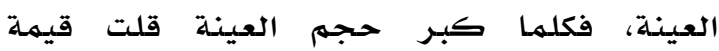
و وإذا نقص حجم العينة ارتفعت قيم (RMSE) (RMSE)

ب-الاختلاف في مستويات الصعوبـة:

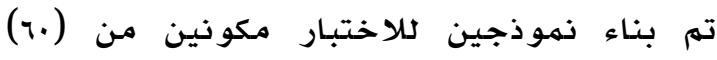
فقرة ومختلفين في مستوى الصعوبة، ثم تم

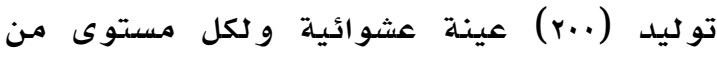

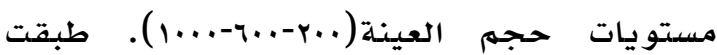

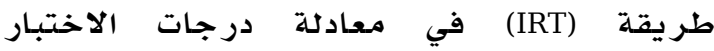
المستخدمة في هذه الدراسة على هذه العينات العشوائية؛ لتقدير جذر متوسط مربعات الفروق في المعادلة، حيث تم التوصل الى النتائج الاتيـة: يوضح الجدول رقم (ع) قيم (RME) لطريقة في معادلة درجات الاختبار الذي يتألف مـن (IRT)

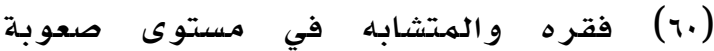
الفقر ات:

جدول ؛.

قيم (RMSE) لطريقة (IRT) في معادلة درجات الاختبار الذي يتألف من ( • Ү) فقره والمختلف في مستوى صعوية الفقرات حجم العينة قيم

يظهر الجدول (عMSE) (عM) أنريقة في معادلة درجات الاختبار الذي يتألف مـن (IRT)

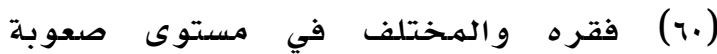

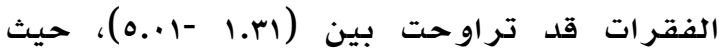

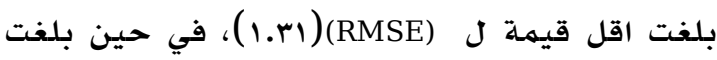
أعلى قيمة (1.0.0)، كذلك يظهر الجدول قيم (RMSE) للمعادلة تنخفض مـع ازدياد حجم

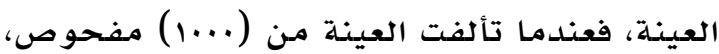

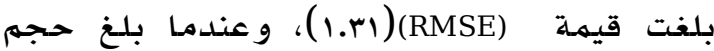

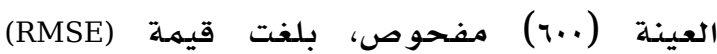

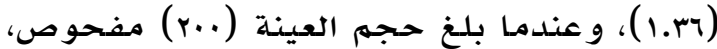

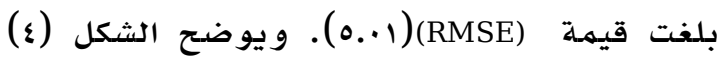
قيم (RMSE) لطريقة (IRT) في معادلة درجات

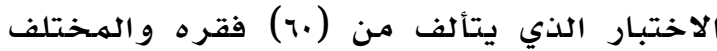
في مستوى صعوبة الفقر ات: 


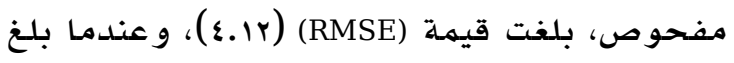

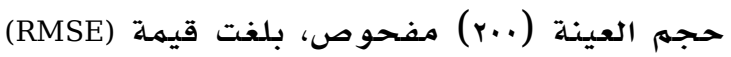

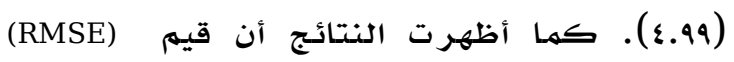

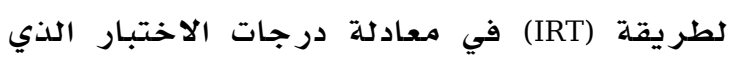

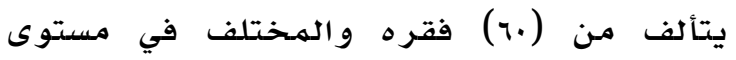

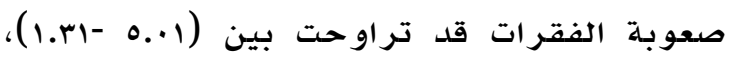

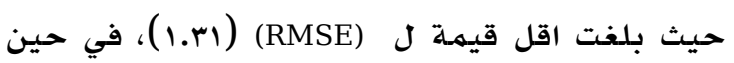

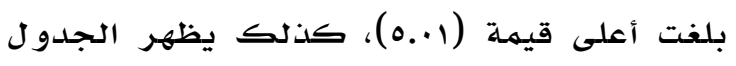

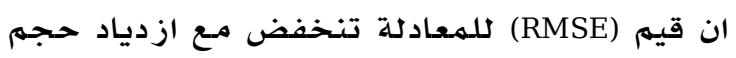

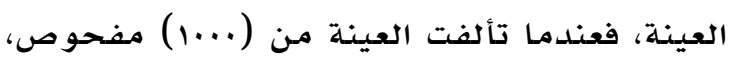

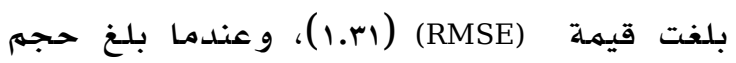

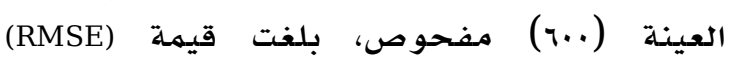

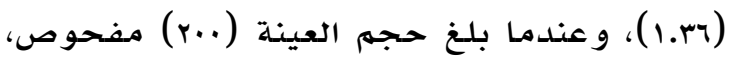

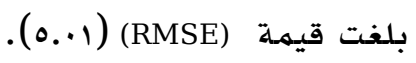
وعند مقارنة نتائج طريقة (ITR) في معادلة درجات الاختبار من خلال حجه العينة أظهرت نتائج الدراسة و تحت ظرف فالاتيار اختلاف حجم العينة،

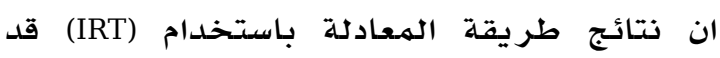

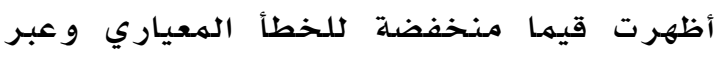

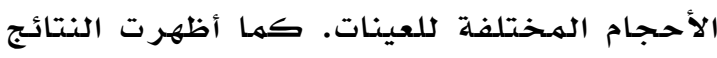
أن حجم العينة يؤثر في قيمة الخطأ المعياري

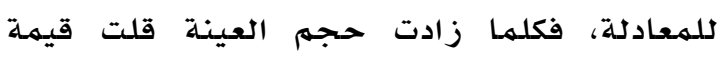

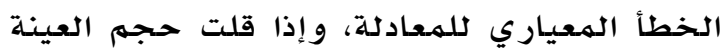

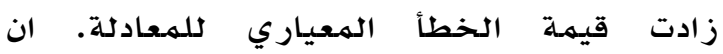
الاختلاف في قيمة الخطأ المعياري للمعادئلة باستخدام طريقة (IRT) يقل تدريجيا عندما فيها

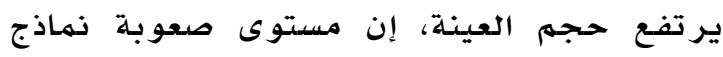
الاختبار له يؤثر على حجم الخطأ المعياري

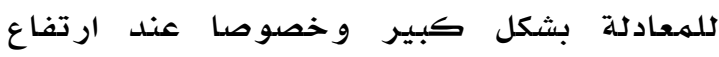

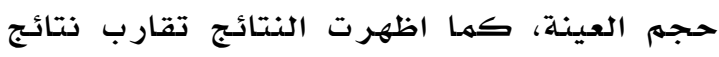
(RMSE)

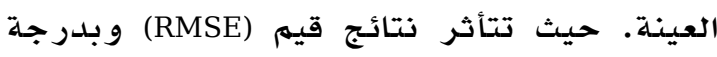

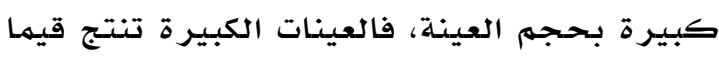

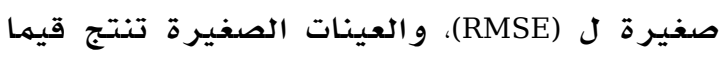
كبيرة لقيم (RMSE)، ونيرة ل

و عند مقارنة نتائج طريقة (ITR) في معادلة درجات الاختبار من خلال حجم العينة وصعوبة فئة

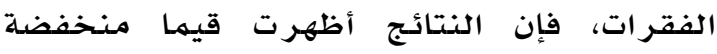

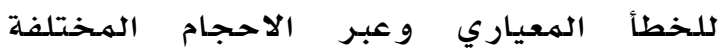
للعينات، فقيم الخطأ المعياري للاختبار الذياري (^r.r)، كذلك يظهر الجدول أن قيمة الخطأ

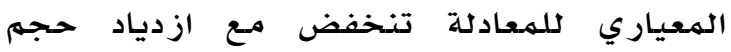

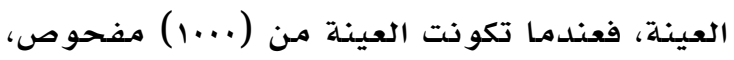

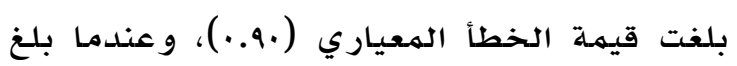

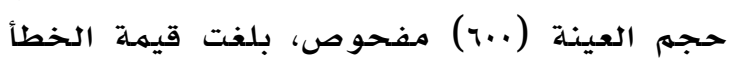

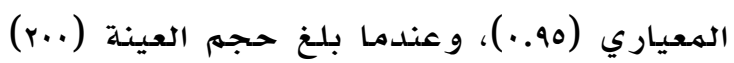

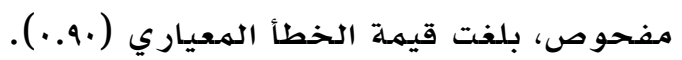

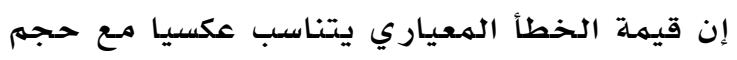
العينة، حيث أنه بزداد بزيادة حجم العيارية العينة، وتقل

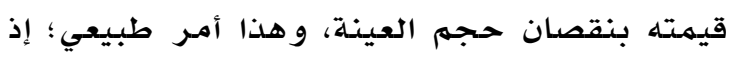

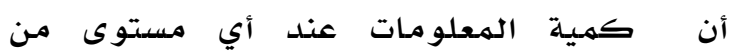

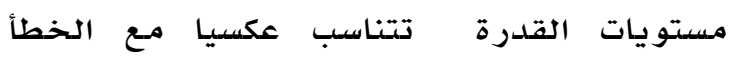

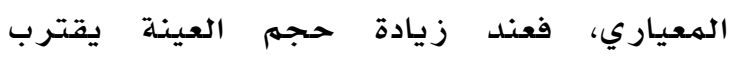

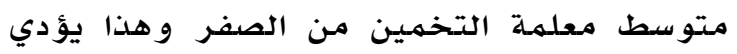

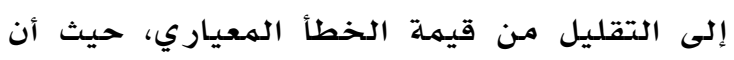

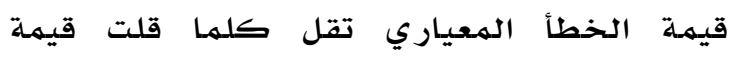
التخمين، وقد يكون سبب ذلك أنه عند الندارئل توليد

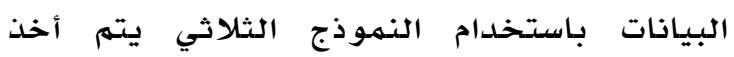

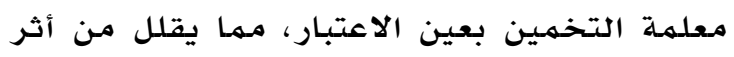

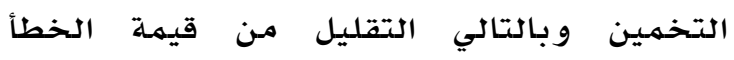
المعياري و البواقي المعيارية.

لقد اتفقت نتائج هذه الدراسة مع نتائج دراسة

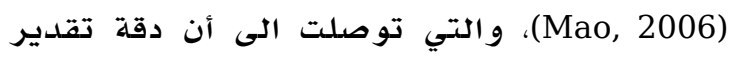

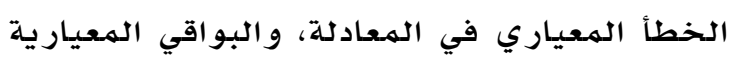
كان أفضل في العينات ذات الحجم الكبير، وهذا ولدا الهيا ما توصلت اليه هذه الدراسة.

مناقشة النتائج المتعلقة بالسؤال الثاني: ما أثر

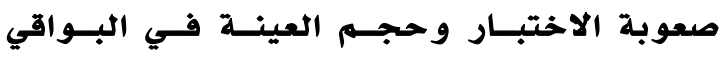

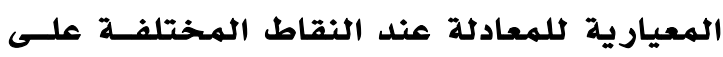

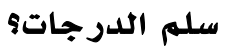

لقد أظهرت النتائج أن قيم (RMSE) لطريقة (IRT)

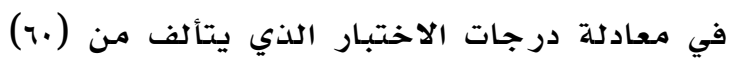

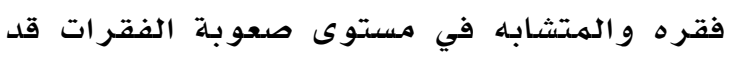

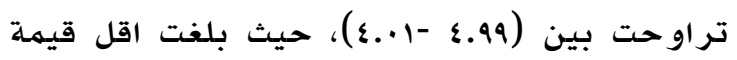

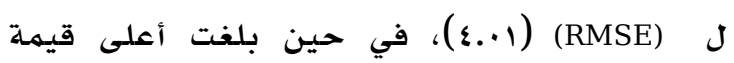

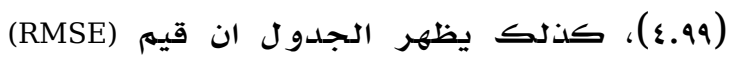

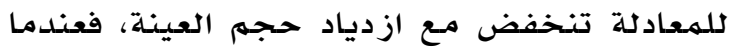

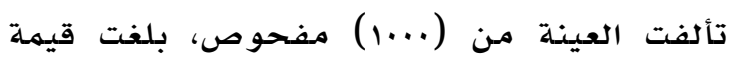

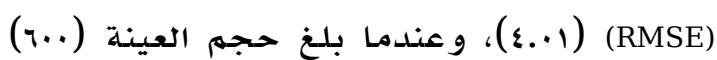


وكذلك بلغت قيمة (RMSE) للعينة التي تكونت

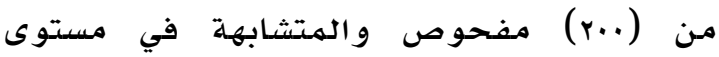

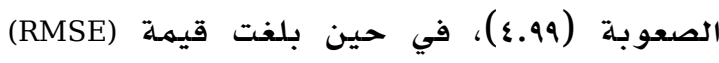

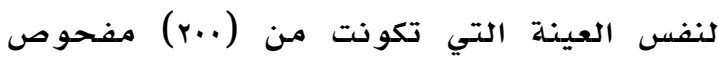

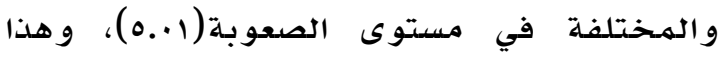

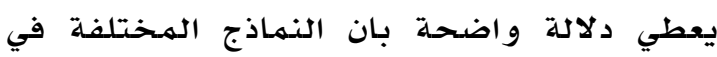
صعوبتها تميل قيم (RMSE) الى الانخفاض عندان الدها

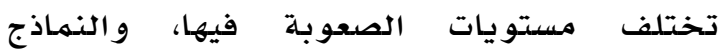

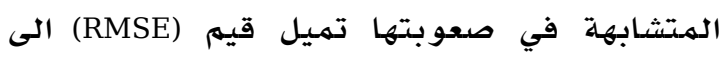

الارتفاع عندما تتشـابه مستويات الصعو بـة فيها. ان قيم SEE, RMSE المستخدم هنا ليست قيما

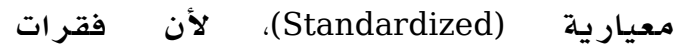

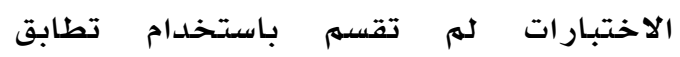

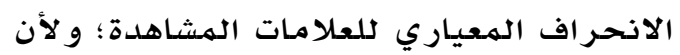

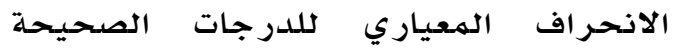
يرتفع مـع زيادة صعوبة الاختبار، فانه يتوقع الادياري أن القيم المعيارية لقيم مMSE سوف تظهر

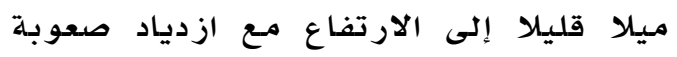

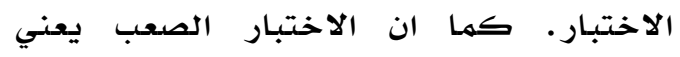

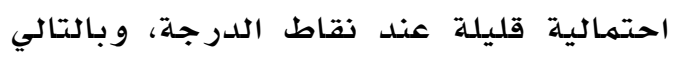

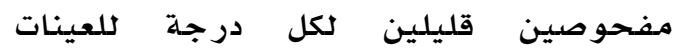

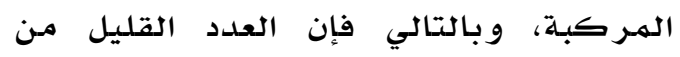

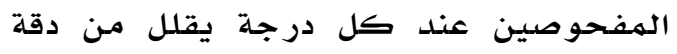
المعادلة عند كل النقاط. لقد اتفقت نتائج هذه الدراسلة مـع نتائج دراسـة (Mao, 2006)، و التي توصلت الى أن دقة تقدير

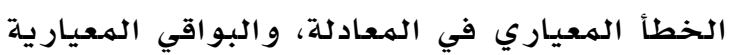
كان أفضل في العينات ذات الحجم الكبير، ووهذا ما توصلت اليه هذه الدر اسـة الديلة

\section{|لاستنتاجات}

خلصت الدراسة الى الاستتتاجات الآتية:

ا- تميل قيم الخطأ المعياري في طريقة

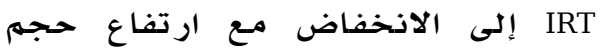

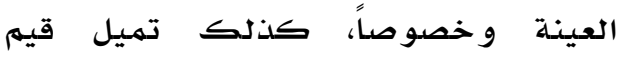

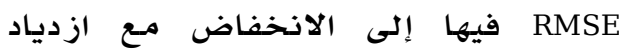

$$
\text { حجم العينة. }
$$

ץ- أظهرت نتائج هذه الدراسة أن أحجام

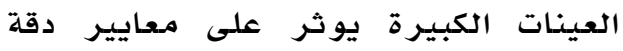

يتكون من (†) فقرة تنخفض عندما تختلف النهماذج في مستوى صعوبتها، فقد بلغت قيمة فيمة الخطأ الهعياري للعينة التي تكونت من (1...

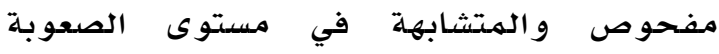
(ץء.r)، في حين فقد بلغت قيمة الخطاً المعياري

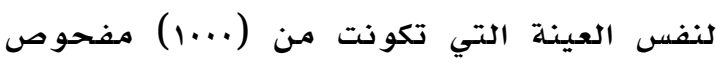

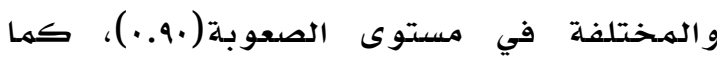
بلغت قيمسة الخطأ المعياري للعينـة التي تكونت

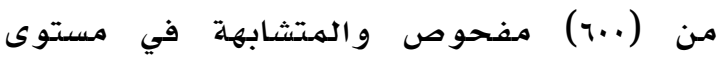

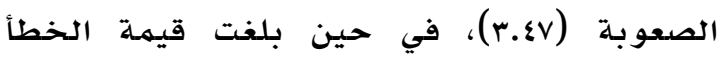

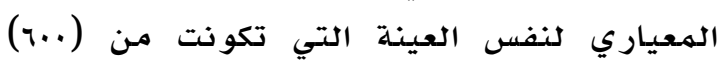

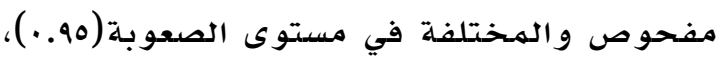
وكذلك بلغت قيمة الخطأ المعياري للعينة

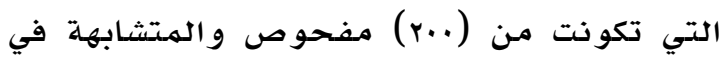

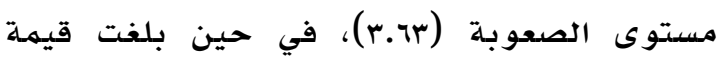

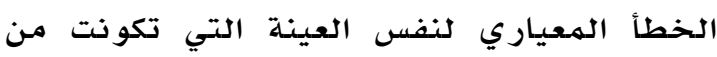

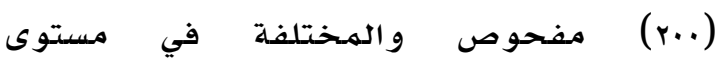

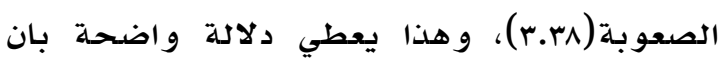

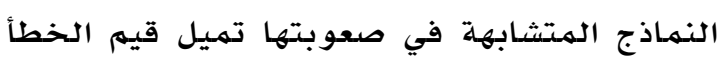
الهعياري الى الانخفاض عندما تتشابه مستويات

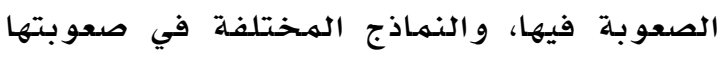

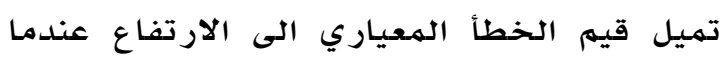
تختلف مستو يات الصعوبة فيها لهيها لهئ أما نتائج (RMSE) تحت الظروف المختتلفة لحجم العينة و التشابه في صعوبة النهاذج، فقد اظهرت ان طريقة المعادلة باستخدام (IRT) اظهرت قيما منخفضة لقيم (RMSE) و عبر الار الاحجام المختلفة للعينات. كمها أظهرت النتائج

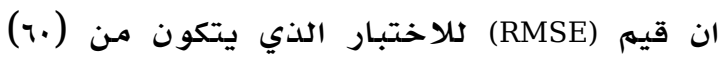
فقرة تنخفض عندما تختلف النماذج في مستوى صعوبتها، فقد بلغت قيمهة (RMSE) للعينـة التي

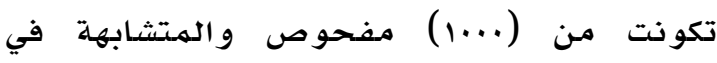

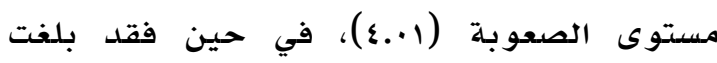

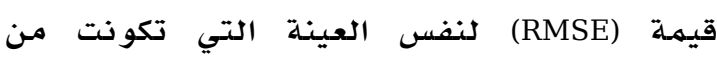

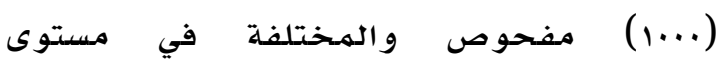
الصعوبة(اس.1)، كها بلغت قيمة (RMSE) للعينة

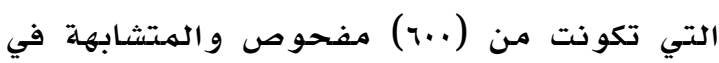

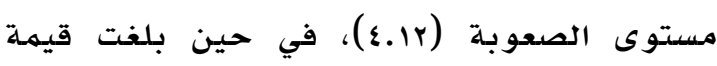
(RMSE)

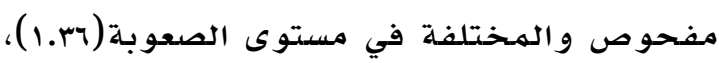


Amanda, A. (2008). A comparison of classical test theory and item response theory methods for equating Number-right scored to formula scored assessments .Unpublished Doctoral Dissertation, University of Kansas, USA.

Baker, F. \& Al-Karni, A. (1991). A comparison of two procedures for Computing IRT equating coefficients. Journal of Education Measurement, 28, 147-162.

Cook, L.L. \& Eignor, D.R. (1991).An NCME instructional module on IRT equating methods. Journal of Education Measurement: Issue and Practice, 10, 37-45.

Hambelton, R. \& Swaminthan, H. (1985). Item Response Theory: Principles and Applications. Boston, Kluwer: Nijhoff Publishing.

Hambelton, R. Swaminathan, H. Rogers, H. (1991). Fundamentals Of item response theory. New York: Sage Publications.

Huigin, H. (2004). Investigation of (IRT)-based equating methods in The presence of outliers. Unpublished Doctoral Dissertation University of Alberta, Canada.

Kolen, M. (1981). Comparison of traditional and item Response Theory methods for equating tests. Journal of Educational Measurement, 18 (1), 1-11.

Kolen, M. (1988).Traditional equating methodology. Educational Measurement: Issues and Practice, 7, 29-36.

Kolen, M. \& Brennan, R. (2004). Test equating, scaling, and linking, (2nd Ed). New York: Springer- Verlag.

Lord, D. (1980). Applications of item Response Theory to Practical Testing Problems. Hillsdale. N.J: Erlbaum.

Mao, X. (2006). An investigation of the accuracy of the estimates of Standard errors for the kernel equating functions. Unpublished Doctoral Dissertation, University of Iowa, USA.

Peterson, N. Kolen, M. \& Hoover, H. (1989). Scaling, Norming and Equating. Educational measurement, Washington D.C: American Council on Education: 241-262.

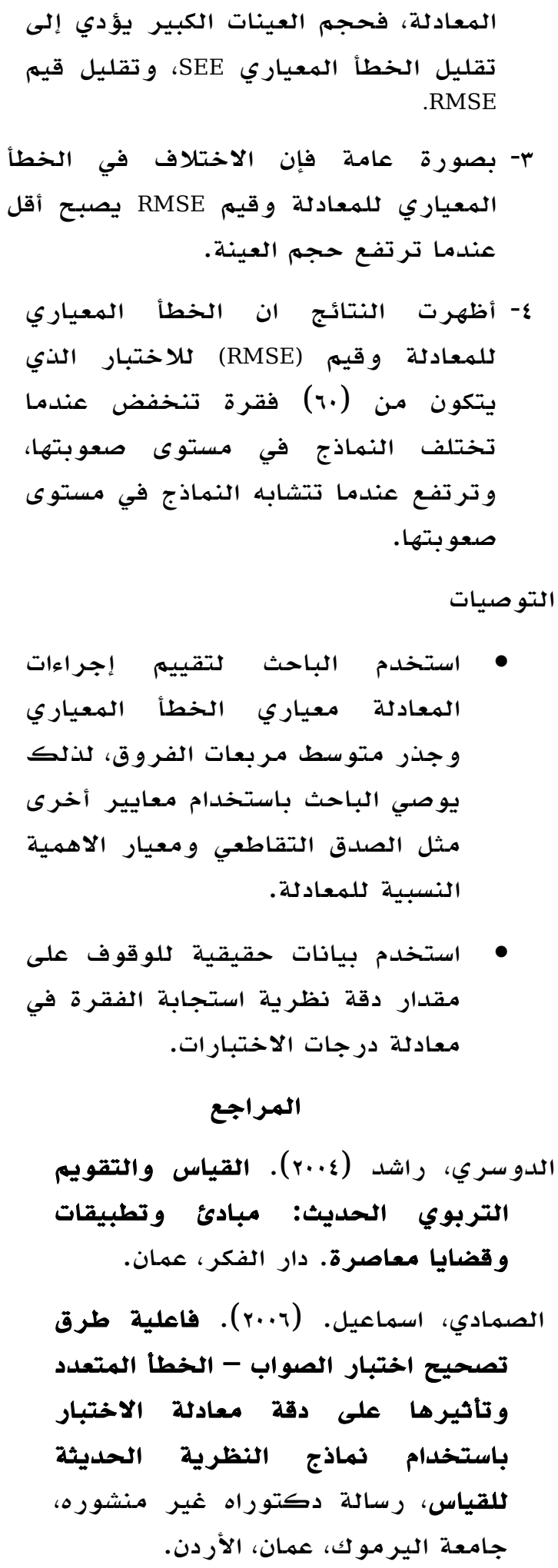


Robert R. (2007). A comparison of item response Theory true score equating and item response theory-Based local equating. Unpublished Doctoral Dissertation, University of Massachusetts, USA.

YoungWoo, C. (2007). Comparison of bootstrap standard errors of equating using (IRT) and equipercentile methods with polytomousscored items under the common-item Nonequivalent- groups design.

Unpublished Doctoral Dissertation, University of Iowa.USA.

Yuki, N. (2008). Comparison of parametric and Nonparametric (IRT) equating methods under the common-item nonequivalent groups design. Unpublished Doctoral Dissertation, University of Iowa.USA. 